\title{
Money, Fame and the Allocation of Talent: Brain Drain and the Institution of Science*
}

\author{
Doh-Shin Jeon ${ }^{\dagger}$ and Domenico Menicucci ${ }^{\ddagger}$ \\ This version: February 5, 2007; The first version: February 1, 2005
}

\begin{abstract}
The earning structure in science is flatter than in the private sector, which could cause a brain drain toward the latter. This paper studies the allocation of talent between both sectors when agents value money and fame. Assuming that the intrinsic performance is a less noisy signal of talent in science than in the private sector, we show that a good institution of science mitigates the brain drain and that introducing extra monetary incentives through the market might induce excessive diversion from pure to applied research. We finally show the optimality of a relatively flat earning structure in science.
\end{abstract}

Keywords: Fame, Science, Brain Drain, Incentives, Asymmetric Information

JEL numbers: D82, H21, H41, J24.

${ }^{*}$ We thank seminar participants at Georgia Institute of Technology, Tinbergen Institute, Universitat Autonoma de Barcelona, Université de Toulouse, ASSET 2004, North American Winter Meeting of Econometric Society 2005 and Conference in Tribute to Jean-Jacques Laffont. We also thank Kosuke Aoki, Bernard Belloc, Antonio Ciccone, Mathias Dewatripont, Ines Macho-Stadler, Andreu Mas-Colell, Mark McCabe, David Pérez-Castrillo, Patrick Rey, Bernard Salanie, Joel Shapiro, Jean Tirole, Jaume Ventura and two anonymous referees for helpful comments. We are very grateful to Paula Stephan for encouragement and useful comments. The first author gratefully acknowledges financial support from the Spanish Ministry of Science and Technology under BEC2003-00412 and the Ramon y Cajal grant.

${ }^{\dagger}$ Corresponding author. Department of Economics and Business, Universitat Pompeu Fabra, and CREA, Ramon Trias Fargas 25-27, 08005 Barcelona, Spain. Email: doh-shin.jeon@upf.edu, phone: (+34) 93542 1657, fax: (+34) 935421746.

${ }_{\ddagger}^{\ddagger}$ Dipartimento di Matematica per le Decisioni, Università degli Studi di Firenze, via C. Lombroso 6/17, 50134 Firenze, Italy. Email: domenico.menicucci@dmd.unifi.it, phone: (+39) 0554796 773, fax: $(+39) 0554796800$. 
"The purest treasure mortal times afford is spotless reputation; that away, men are but gilded loam or painted clay." - William Shakespeare in Richard II

\section{Introduction}

Inducing talented people to become scientists is a national priority for all countries since a nation's economic future is closely linked to its scientific capacity in today's knowledge-based economy. However, the private incentive for a talented agent to choose a scientific career may not be well aligned with the social incentive because she has many other attractive alternatives. For instance, in the U.S., bright young people with college degrees can pursue graduate studies in one of the major professional fields such as medicine, law and business. Compared to advanced study in science, these fields promise a much shorter period in school and substantially more lucrative job prospects. ${ }^{1}$ This might generate a brain drain from the science sector to the private sector. Currently, both in the U.S. and in Europe, there are concerns about a shortage of scientists and engineers. $^{2}$

This paper studies the allocation of talent between the science sector and the private sector in an economy in which each agent makes an occupational choice between becoming a scientist and becoming a professional. We make a departure from the conventional assumption that only monetary payoffs matter and assume that each agent values fame as well. We use a rather narrow definition of fame as the amount of peer recognition that an agent receives as a function of her performance and study the allocation of talent by focusing on the difference between the two sectors in terms of the mapping from talent to performance.

A fundamental difference between the two sectors is that agents in the private sector can more or less appropriate their contribution to the society through profits while scientists (in pure science) cannot because of the public good nature of science. This difference in turn generates another important difference in terms of allocation of fame;

\footnotetext{
${ }^{1}$ Butz et al. (2003) compare an estimate of annualized earnings for Ph.D.s with earnings of professional degree holders in U.S. such as MDs, DDSs, DVMs, JDs, and MBAs and find that professional degree holders earn more at nearly every age and considerably more over an entire life career.

${ }^{2}$ For instance, the New York Times (May 5, 2004) reports that "The Unites States faces a major shortage of scientists because too few Americans are entering technical fields and because international competition is heating up for bright foreigners who once filled the gap," referring to the report of National Science Board (2004). Concerning Europe, see the recent report of the European Commission (2003).
} 
the market provides an objective measure of each agent's performance (i.e. her profit) and accordingly distributes fame while the science sector, in order to have an objective measure of each scientist's performance, needs an institution that certifies the scientific contribution of each work. According to the sociologists of science such as Merton (1957, 1973), science is a social institution that defines originality as a supreme value and allocates fame and recognition according to priority so that the augmenting of knowledge and the augmenting of personal fame go hand in hand. ${ }^{3}$ This incentive role of peer recognition for scientists is also recognized by Paul Samuelson who said "In the long run, the economic scholar works for the only coin worth having - our own applause" (Merton 1968, 341).

We build a simple model in which each agent has private information about her level of talent and her intrinsic preference between the two occupations (professional and scientist) and the government builds a public science sector. An agent can be either talented or not while her occupational preference has support wide enough that there is a positive fraction of both talented and not-talented agents in each sector. We focus on the refereeing and publication process of the institution of science and define the quality of the institution as the quality of the mapping from intrinsic outcomes of scientific work to perceived outcomes. The perceived outcome of each scientist is observed by the government and her peers: the former provides monetary rewards and the latter provide non-monetary rewards (i.e. peer recognition) depending on the perceived outcome. In contrast, in the case of professionals, we do not make any distinction between intrinsic and perceived outcomes since we assume that each professional's profit is observable.

We investigate three related issues in this setting. First, we study the brain drain generated by lower monetary returns to talent in science and how it is affected by peer recognition and the quality of the institution of science. Second, we study how the availability of additional monetary incentives through the market (for instance, from licensing patents) affects the brain drain and social welfare. Last, we consider a more general framework in which the government uses two instruments (wages and research grants) in order to investigate whether a relatively flat earning structure in science can arise as an optimal feature.

In the absence of fame, a brain drain toward the private sector arises in our basic

\footnotetext{
${ }^{3}$ According to Merton (1957), the institution of science has developed a priority-based system for allocating (honorific) rewards. Heading the list of recognition is eponymy, the practice of affixing the name of the scientist to all or part of what she has found, as with the Copernican system, Hooke's law and so on. Other rewards include prizes, medals, and memberships in honorary academies. Last, publication and citation constitute rewards available to most scientists.
} 
model because we assume that the monetary reward to talent is higher in the private sector than in the science sector. This assumption is true in (Continental) Europe in which most institutions of higher education follow a system based on seniority where performance has virtually no impact on salary. ${ }^{4}$ It also holds in the U.S. since the profile of earnings in science is known to be rather flat ${ }^{5}$ while the returns to talent in the private sector are large. ${ }^{6}$ We could find only weak evidence of the brain drain in the U.S.: the number of US citizens with very high GRE-score (>750) headed for science and engineering graduate studies declined by more than $8 \%$ between 1992 and 2000 (Zumeta and Raveling 2002). ${ }^{7}$ However, predictions of a shortage of scientists both in Europe and the U.S. on the one hand and increasing rewards to talent in the private sector $^{8}$ on the other hand well justify our concerns about the brain drain.

Central in our model is the assumption that the intrinsic outcome of a scientist is a less noisy signal of talent than that of a professional in the private sector. This gives peer recognition a potential role in attracting talent to science. We have three justifications for this assumption. First, research is traditionally individual work while business is team work: the average number of authors per research paper is four (Adams et al. 2005) while production and marketing processes of a firm involve a much larger number of people. Second, originality has a supreme value in science while in other professions without much team work such as lawyers and medical doctors, tasks are relatively routine and repetitive: a path-breaking discovery is a clear sign of genius while one does not need

\footnotetext{
${ }^{4}$ See Aghion and Cohen (2004), Perotti (2002) and the Wall Street Journal Europe (September 3, 2004). For instance, according to Perotti's study of the promotion to full professorship in economics in Italy, (i) an outsider needs 13 more refereed publications than an insider in order to compensate for the latter's advantage, and (ii) even in the competition among outsiders, the effect of a publication in a high-quality journal is not statistically different from the effect of a publication in a low-quality journal.

${ }^{5}$ The average full professor earns only about 38 to 109 percent more than the average new assistant professor depending on the discipline (Ehrenberg 1991). Even the best-paid professor in the fifty leading universities seldom receives three times as much salary as the worst-paid professor (Stigler 1988).

${ }^{6}$ Although Butz et al. show that professionals make more money than Ph.D.s, there is no empirical work comparing the monetary rewards to talent in both sectors. However, top money managers, for instance, can earn more than $\$ 250$ million a year (New York Times, August 5, 2005) and it is needless to say that no professor's salary can be that high.

${ }^{7}$ They also find that among US citizens and long-term residents, the share of the science and engineering majors from leading colleges or universities planning immediate advanced study in a science or engineering discipline fell from $17 \%$ in 1984 to $12 \%$ in 1998 .

${ }^{8}$ See the literature on superstars (Rosen 1981), complementarity and positive sorting (Kremer 1993), skill-biased technological changes (Caselli 1999) and the finance literature on CEO compensation (Murphy 1999).
} 
to be a genius in order to perform routine tasks well. Last, openness (i.e. making one's discovery public) is the norm in science because of priority recognition while secrecy is the norm in the private sector because of profit seeking, which makes the filtering out of noise in performance more difficult in the private sector. As a consequence of these assumptions, the expected non-pecuniary reward to talent in terms of peer recognition is higher in science than in the private sector when the institution of science is perfect.

As a benchmark, we study the first-best allocation of talent when the government can observe each agent's level of talent and occupational preference and dictate her occupational choice. It is widely believed that real innovation in science depends less on the many "worker bees" than on the presence of a small number of great minds. This, together with the huge positive externality of a great scientific discovery on society, would make talent more productive in science than in the private sector. Then, in the first-best outcome, the fraction of scientists is higher among talented agents than among not-talented agents.

Under incomplete information about talent, the government can make the wage of a scientist depend only on her perceived outcome. We assume an upper bound on the wage differential within the science sector that makes the monetary reward to talent lower in science than in the private sector. In the absence of utility from fame, this leads to a brain drain toward the private sector. However, when agents derive utility from fame, a good institution of science can mitigate the brain drain (and may even achieve the first-best allocation) by providing a non-monetary reward to talent higher than the one in the private sector while a bad institution of science exacerbates it.

In Section 4, we introduce extra monetary incentives through the market into our model. For instance, the Bayh-Dole Act (1980) was introduced in the U.S. to foster interactions between academia and the business community. The Act enables universities to claim ownership of the intellectual property rights generated from federally funded research and provides scientists with opportunities to earn money, and most OECD countries emulated the American experience. We study how the availability of extra monetary rewards from licensing patents affects scientists' research pattern and what its consequence is on brain drain and on social welfare. However, we depart from a simple linear relationship between basic and applied science and introduce what we call the Pasteur's Quadrant (PQ) ${ }^{9}$ coefficient to capture the degree to which basic research can

\footnotetext{
${ }^{9}$ Pasteur's Quadrant is the title of the book written by Stokes (1997) who mainly argues against the standard distinction between basic and applied science as two distinct categories by pointing out that Pasteur made pioneering discovery although he was motivated to find solutions to practical problems.
} 
generate patentable scientific knowledge. We find that when the PQ coefficient is high, introducing the licensing opportunity does not affect research patterns, reduces the brain drain and increases social welfare. In contrast, when the coefficient is low, introducing the licensing opportunity can induce excessive diversion from pure to applied research, which might reduce social welfare even while it reduces the brain drain. We also find that the licensing opportunity is more likely to enhance welfare when the institution of science is good since a good institution of science makes excessive diversion less likely.

In Section 5, we study the optimal balance between monetary and non-monetary incentives in science in a general setting in which the government uses two instruments: wages and research grants. We assume that there are no restrictions on wages (in order to eliminate the issue of brain drain) and that the government observes an individual signal correlated with a scientist's talent and awards research grants as a function of the signals. We characterize the optimal balance between monetary and non-monetary incentives in terms of what we call the benefit-adjusted social marginal cost of providing grants, which decreases with the quality of the institution of science. This implies that as the quality of the institution increases, one should increase the relative weight of the non-monetary incentive over the monetary one and, in particular, we show that a relatively flat earning structure in science is optimal when the institution of science is good and scientists highly value priority recognition.

Although there are papers on the economics of science that refer to the sociology of science (Dasgupta and Paul 1987 and 1994, Stephan 1996), they have not built any formal model to study the allocation of talent between the private sector and the science sector. Furthermore, the existing literature on the brain drain under asymmetric information initiated by Kwok and Leland (1982) studies only the migration from one country to another but does not study the brain drain from the science sector to the private one in a closed economy.

In terms of modeling incentives from non-monetary rewards, our paper is related to Benabou and Tirole (2006) and Besley and Ghatak (2005). The former builds a signaling model in which reputation from social groups provides incentives to engage in pro-social behavior such as blood donation. The latter studies the incentive issues in mission-oriented organizations such as schools and find a potential benefit of the market in inducing a good match among the principals and the agents with different mission preferences. Both papers focus on how non-monetary rewards can help to solve moral

Rosenberg (2004) also argues in a similar spirit that causation between science and technology runs both ways. 
hazard while we focus on how non-monetary rewards can help to screen agents with different levels of talent.

With respect to the principal-agent theory, our paper is related to the literature on non-responsiveness (Guesnerie and Laffont 1984), which focuses on a strong conflict between the allocation preferred by the principal and the allocations implementable under incentive constraints. In our paper, the conflict arises since the principal (the government) wants the fraction of scientists among talented agents to be larger than the fraction among not-talented agents while the incentive constraints may force the principal to implement only those allocations in which the latter is larger than the former. Our problem is symmetric to the one analyzed by Jeon and Laffont (1999, 2006) who study the optimal mechanism for downsizing the public sector when workers have private information on their productivity although they consider neither science nor fame.

Regarding the papers on the allocation of talent (Acemoglu and Verdier 1998 and 2000, Murphy et al. 1991, Grossman and Maggi 2000, and Grossman 2004), none of them models fame or studies the allocation of talent between the science sector and the private sector.

The paper is organized as follows. Section 2 describes the basic model. Section 3 analyzes the model and focuses on the brain drain. Section 4 analyzes how the availability of extra monetary incentives through the market affects the research pattern, the brain drain and social welfare. Section 5 analyzes the optimal balance between monetary and non-monetary incentives in science. Concluding remarks are gathered in Section 6. All the proofs are in Appendix, which is available on this journal's website.

\section{The basic model}

In this section, we describe the basic model that is used in section 3 . In section 4 and section 5 , we extend the basic model in different directions.

\subsection{Occupations, adverse selection and outcomes}

There is a mass one of risk-neutral agents in the economy. Let $I$ be the set of all the agents. Each agent should make an occupational choice between becoming a professional in the private sector and becoming a scientist. Although in reality a lot of scientific research is carried out by the private sector, in our model "becoming a professional" 
is equivalent to "going to the private sector". Agent $i$ has private information about her level of talent (or intelligence), denoted by $\theta_{i}$, and her intrinsic preference between the two professions, denoted by $\gamma_{i}$. For simplicity, $\theta_{i}$ can take on two values: $\theta_{i} \in$ $\Theta \equiv\{T, N\} ; \theta_{i}=T$ is called a talented type and $\theta_{i}=N$ is called a not-talented type. Since we focus on the choice between professional and scientist, we do not lose much generality by considering a one-dimensional talent space. ${ }^{10} \theta_{i}$ is identically and independently distributed. Let $\nu \in(0,1)$ denote the probability that $\theta_{i}=T$; hence $1-\nu=\operatorname{Pr}\left\{\theta_{i}=N\right\}$. When we do not refer to a specific agent, we drop the subscript $i$; for instance, we use $\theta$ instead of $\theta_{i}$.

$\gamma_{i}$ represents the difference between the intrinsic (non-monetary) pleasure that agent $i$ derives from being professional and the intrinsic pleasure from being scientist such that $\gamma_{i}<0$ means that agent $i$ has a relative preference for scientist over professional. For instance, the intrinsic pleasure from becoming scientist can include love of science or satisfaction from solving puzzles (Levin and Stephan 1991). Since what matters for social welfare is each agent's choice between the two professions and intrinsic pleasure affects agent $i$ 's choice only through the relative pleasure $\gamma_{i}$, we normalize, without loss of generality, each agent's absolute pleasure from becoming scientist at zero. For simplicity, we assume that $\gamma_{i}$ is identically and independently distributed over $i$ according to a uniform distribution with support $[-\gamma, \gamma]$ and that there is no correlation between $\theta_{i}$ and $\gamma_{i}$. We discuss a case of correlation in section 6 .

Let $O_{i} \in\{R, S\}$ represent agent $i$ 's occupational choice: $O_{i}=R\left(O_{i}=S\right)$ when she becomes professional (scientist). We assume for simplicity that the outcome that an agent realizes after choosing an occupation has a binary support: it can be high or low. More precisely, a type $\theta$ scientist realizes a high outcome (i.e. a path-breaking discovery) with probability $p_{\theta}^{S}$ and a low outcome (i.e. an ordinary discovery) with probability $1-p_{\theta}^{S}$. We focus on pure scientific research that does not produce any direct monetary gain to the scientist but increases the productive potential of the future economy. We assume that the social monetary value of a path-breaking discovery is $s^{H}>0$ and that of an ordinary discovery is $s^{L} \in\left(0, s^{H}\right)$. A type $\theta$ professional produces a high profit $\pi^{H}>0$ with probability $p_{\theta}^{R}$ and a low profit $\pi^{L} \in\left(0, \pi^{H}\right)$ with probability $1-p_{\theta}^{R}$. Obviously, $\Delta p^{O} \equiv p_{T}^{O}-p_{N}^{O}>0$ for $O \in\{R, S\}$. Let $S_{\theta} \equiv p_{\theta}^{S} s^{H}+\left(1-p_{\theta}^{S}\right) s^{L}$ and $\Pi_{\theta} \equiv p_{\theta}^{R} \pi^{H}+\left(1-p_{\theta}^{R}\right) \pi^{L}$.

\footnotetext{
${ }^{10} \mathrm{By}$ contrast, if we study a choice between entrepreneur and researcher, we need to consider a multi-dimensional type space since to be a good entrepreneur, one needs mutiple skills (Lazear 2005).
} 


\subsection{Institution of science and fame}

There are many factors affecting the quality of the institution of science. In this paper, we take a narrow angle and focus on the refereeing and publication process. We define the quality of the institution of science as the quality of the mapping from the intrinsic outcomes of scientists to the perceived outcomes. The intrinsic outcome refers to the original value of a scientific work, and the perceived outcome refers to the certification label that the work receives through the refereeing and publication process. The intrinsic outcome is either high or low as described in section 2.1. We assume that the perceived outcome is either high or low as well. Let $q_{r} \in\left[\frac{1}{2}, 1\right]$ denote the probability that a high intrinsic outcome is perceived as high, which is assumed for simplicity to be equal to the probability that a low intrinsic outcome is perceived as low. Therefore, $q_{r}$ is a measure of the quality of the institution of science. ${ }^{11}$

Regarding the definition of fame, we consider an individual's fame as the recognition she gets from her peers. The amount of recognition that agent $i$ receives is assumed to increase with the level of her outcome perceived by the peers. For simplicity, we assume that if agent $i$ 's perceived outcome is low, she gets zero recognition while if it is high, she gets a unit amount of recognition. ${ }^{12}$ Therefore, the expected fame of a type $\theta$ scientist is $\beta_{\theta} \equiv p_{\theta}^{S} q_{r}+\left(1-p_{\theta}^{S}\right)\left(1-q_{r}\right)$, the probability that she will have a high perceived outcome. For a professional we suppose that her outcome is publicly observable; thus the expected fame for a type $\theta$ professional is $p_{\theta}^{R}$.

We make the following assumption:

Assumption 1: The intrinsic outcome is a less noisy signal of talent in science than in the private sector (i.e. $\Delta p^{S}>\Delta p^{R}$ ).

We gave in the introduction three reasons for why assumption 1 is likely to hold. This assumption implies that when the quality of the institution of science is perfect (i.e. $q_{r}=1$ ), the difference between a talented agent's expected fame and that of a nottalented agent is larger in the science sector than in the private sector; in other words, the non-pecuniary reward to talent in terms of fame is higher in the former than in the latter.

Agent $i$ 's payoff $U_{i}$ is given as follows:

$$
U_{i}=m_{i}+\alpha f_{i}+\gamma_{i} \mathbf{1}_{\left[O_{i}=R\right]}
$$

\footnotetext{
${ }^{11} q_{r}$ means quality of refereeing.

${ }^{12}$ The quality of the institution of science can affect the amount of recognition that one obtains from a high perceived outcome. Including this aspect into our model does not affect our results qualitatively.
} 
where $m_{i}$ is her monetary income, $\alpha(\geq 0)$ is the weight parameter for fame, and $f_{i}$ is her fame.

\subsection{Government}

The government pays wages to induce agents to become scientists and can make a scientist's wage contingent on her perceived outcome. Let $w$ be the basic salary that every scientist earns and $b \geq 0$ the bonus that a scientist receives if her perceived outcome is high; the bonus can be interpreted as the increase in salary following a promotion resulting from good publications.

We assume that there is an upper bound on $b$, denoted by $\bar{b}>0$, that satisfies the following assumption.

Assumption 2: The monetary reward to talent is higher in the private sector than in science: $\Delta p^{R}\left(\pi^{H}-\pi^{L}\right)>\Delta p^{S} \bar{b}$.

The inequality says that the difference between a talented professional's expected profit and that of a not-talented one is higher than the difference between a talented scientist's expected monetary income and that of a not-talented one, even when $q_{r}=1$. This implies that the monetary reward to talent is larger in the private sector than in the science sector for any value of $q_{r} \in\left[\frac{1}{2}, 1\right]$. Assumption 2 captures the stylized fact that monetary incentives are lower-powered in academia than in the private sector. We provided detailed justifications of the assumption in the introduction.

In order to describe how an agent chooses her occupation, we notice that the payoff that a type $\theta$ agent with $\gamma_{i}$ expects to have after becoming a professional is given by $\Pi_{\theta}+\gamma_{i}+\alpha p_{\theta}^{R}$, ${ }^{13}$ while her payoff if she becomes a scientist is $w+\beta_{\theta}(b+\alpha)$. Thus, the agent chooses to become a scientist if the following inequality holds:

$$
w+\beta_{\theta}(b+\alpha) \geq \Pi_{\theta}+\gamma_{i}+\alpha p_{\theta}^{R}
$$

Let $\phi_{T}\left(\phi_{N}\right)$ denote the fraction of the talented (not-talented) agents becoming scientists. Social welfare, denoted by $S W$, is given as follows:

$$
S W \equiv \nu\left(1-\phi_{T}\right) \Pi_{T}+(1-\nu)\left(1-\phi_{N}\right) \Pi_{N}+\nu \phi_{T} S_{T}+(1-\nu) \phi_{N} S_{N}+\int_{I_{R}} \gamma_{i} d i
$$

\footnotetext{
${ }^{13}$ If we consider agent $i$ 's utility from entering the private sector as her reservation utility, it is type-dependent through $\theta_{i}$ and has a random component $\gamma_{i}$ as in Rochet and Stole (2002).
} 
where $I_{R}$ is the set of agents who choose a professional career. We assume that the government maximizes the above objective regardless of whether $\alpha>0$ or $\alpha=0$. In other words, we suppose that the government does not care about recognition per se but cares about it only because it affects the individual professional choices, and thus $\phi_{T}$ and $\phi_{N}$. In reality, it is hard to measure the aggregate level of fame or recognition in an economy and to make the government accountable for it. ${ }^{14}$

\subsection{Timing}

We consider a game with the following timing:

1. For each $i \in I$, nature draws $\theta_{i}$ and $\gamma_{i}$ and they become agent $i$ 's private information.

2. The government announces $\{w, b\}$.

3. Each agent makes her occupational choice.

4. Each agent's outcome is realized.

5. Each scientist receives the basic wage $w$ and, in case of a high perceived outcome, also the bonus $b$.

\section{Allocation of talent and brain drain}

\subsection{First best benchmark: complete information outcome}

In this subsection we derive as a benchmark the first best allocation of talent, the allocation that maximizes social welfare when the government has complete information about each agent $i$ 's talent $\theta_{i}$ and occupational preference $\gamma_{i}$ and can dictate each agent's occupational choice. In the next subsection we examine a more realistic setting in which each agent $i$ has private information about $\left(\theta_{i}, \gamma_{i}\right)$ and makes her occupational choice.

It is straightforward to see that to realize a given $\phi_{\theta} \in(0,1)$ for $\theta \in\{T, N\}$, it is socially optimal that there exists a cut-off type $\gamma_{\theta}=\gamma\left(2 \phi_{\theta}-1\right) \in(-\gamma, \gamma)$ such that all type $\theta$ agents with $\gamma_{i} \geq \gamma_{\theta}\left(\gamma_{i}<\gamma_{\theta}\right)$ become professional (scientist). Therefore, $\left(\phi_{T}, \phi_{N}\right) \in[0,1]^{2}$ represents an allocation of talent between the two occupations and the sum of the agents' intrinsic pleasure from their occupations given $\left(\phi_{T}, \phi_{N}\right)$ is

$$
\int_{I_{R}} \gamma_{i} d i=\nu \int_{\gamma\left(2 \phi_{T}-1\right)}^{\gamma} \frac{z}{2 \gamma} d z+(1-\nu) \int_{\gamma\left(2 \phi_{N}-1\right)}^{\gamma} \frac{z}{2 \gamma} d z=\gamma\left[\nu \phi_{T}\left(1-\phi_{T}\right)+(1-\nu) \phi_{N}\left(1-\phi_{N}\right)\right] .
$$

\footnotetext{
${ }^{14}$ Furthermore, what people care about is often relative recognition rather than absolute recognition and when we aggregate relative recognition, its sum is zero by definition.
} 
Hence, social welfare is given as follows: ${ }^{15}$

$$
\begin{gathered}
S W\left(\phi_{T}, \phi_{N}\right) \equiv \nu\left(1-\phi_{T}\right) \Pi_{T}+(1-\nu)\left(1-\phi_{N}\right) \Pi_{N}+\nu \phi_{T} S_{T}+(1-\nu) \phi_{N} S_{N} \\
+\gamma\left[\nu \phi_{T}\left(1-\phi_{T}\right)+(1-\nu) \phi_{N}\left(1-\phi_{N}\right)\right] .
\end{gathered}
$$

The government maximizes $S W$ with respect to $\left(\phi_{T}, \phi_{N}\right)$ in $[0,1]^{2}$. The first order conditions (for an interior allocation) are given as follows: ${ }^{16}$

$$
\begin{aligned}
\Pi_{T}+\gamma\left(2 \phi_{T}-1\right) & =S_{T}, \\
\Pi_{N}+\gamma\left(2 \phi_{N}-1\right) & =S_{N} .
\end{aligned}
$$

These conditions show that, for each $\theta \in\{T, N\}$, the social marginal value that the cutoff type produces as a professional is equal to the one she produces as a scientist, where social marginal values take into account the intrinsic preferences for occupations. The next proposition characterizes the first-best allocation of talent, denoted by $\left(\phi_{T}^{F B}, \phi_{N}^{F B}\right) .{ }^{17}$

Proposition 1 (The first-best) The first-best allocation of talent is given by

$$
\phi_{T}^{F B}=\frac{\gamma-\Pi_{T}+S_{T}}{2 \gamma}, \quad \phi_{N}^{F B}=\frac{\gamma-\Pi_{N}+S_{N}}{2 \gamma} .
$$

In $\left(\phi_{T}^{F B}, \phi_{N}^{F B}\right)$, the fraction of scientists is larger among talented agents than among not-talented agents if and only if talent is more productive in the science sector than in the private sector: $\phi_{T}^{F B}>\phi_{N}^{F B}$ if and only if $S_{T}-S_{N}>\Pi_{T}-\Pi_{N}$.

We note that the first best allocation does not depend on $\alpha$ since the objective of the government is independent of $\alpha$ and there is no constraint on the allocation of talent that it can choose. In the rest of the paper we make the following assumption, which implies $\phi_{T}^{F B}>\phi_{N}^{F B}$ :

Assumption 3: Talent is more productive in the science sector than in the private sector: $S_{T}-S_{N}>\Pi_{T}-\Pi_{N}$.

\footnotetext{
${ }^{15}$ Recall that social welfare does not depend on fame, as we explained in subsection 2.3.

${ }^{16}$ Throughout the paper we assume that the optimal allocations are interior; in the proofs in the appendix we describe the conditions under which this is the case. Allowing for corner allocations is straightforward but complicates the exposition without yielding any additional insight.

${ }^{17}$ We remark that it is possible to implement the first best allocation by using a market mechanism under weaker assumptions on the government's information and power. More precisely, it suffices that the government observes the talent of each agent and makes an agent's wage depend on her talent.
} 
Note that $S_{T}-S_{N}=\Delta p^{S}\left(s^{H}-s^{L}\right)$. It is widely believed that real innovation in science depends less on the many "worker bees" than on the presence of a small number of great minds (i.e. $\Delta p^{S}$ is high). This fact, together with the huge positive externality of a great scientific discovery on society (i.e. $s^{H}-s^{L}$ is high), makes assumption 3 quite plausible.

\subsection{Incomplete information outcome: with and without fame}

In this subsection we assume that each agent $i$ privately observes $\left(\theta_{i}, \gamma_{i}\right)$ and chooses her occupation. We study the government's optimal choice of $(w, b)$, and in particular, we focus on how the incomplete information, together with assumption 2 and the condition $0 \leq b \leq \bar{b}$, restricts the set of implementable allocations of talent.

We start by noticing that in order to achieve an interior allocation of talent $\left(\phi_{T}, \phi_{N}\right) \in$ $(0,1)^{2}$, it is necessary that $(w, b)$ satisfy the following incentive constraints:

$$
\begin{array}{cc}
\left(I C_{T}\right) & \Pi_{T}+\alpha p_{T}^{R}+2 \gamma \phi_{T}-\gamma=w+\beta_{T}(b+\alpha) \\
\left(I C_{N}\right) & \Pi_{N}+\alpha p_{N}^{R}+2 \gamma \phi_{N}-\gamma=w+\beta_{N}(b+\alpha) .
\end{array}
$$

If $\left(I C_{\theta}\right)$ holds, all type- $\theta$ agents with intrinsic occupational preference higher (lower) than $2 \gamma \phi_{\theta}-\gamma$ become professionals (scientists) since the type with preference $2 \gamma \phi_{\theta}-\gamma$ is indifferent between the two occupations. Then, the fraction of type- $\theta$ agents becoming scientists is just $\phi_{\theta}$.

In order to solve (4)-(5) with respect to $(w, b)$, we notice that $\beta_{T}-\beta_{N}=\Delta p^{S}\left(2 q_{r}-1\right)$, and thus $q_{r}>\frac{1}{2}$ implies $\beta_{T}>\beta_{N}$. Therefore it is possible to solve (4)-(5) with respect to $(w, b)$ as long as $q_{r} \in\left(\frac{1}{2}, 1\right]$, and the solution is given by

$$
w=\frac{\beta_{T} A_{N}-\beta_{N} A_{T}}{\beta_{T}-\beta_{N}}, \quad b=\frac{A_{T}-A_{N}}{\beta_{T}-\beta_{N}},
$$

where $A_{\theta}$ is the left hand side in $\left(I C_{\theta}\right)$ minus $\beta_{\theta} \alpha$. Hence, for any given allocation $\left(\phi_{T}, \phi_{N}\right)$ including the first best $\left(\phi_{T}^{F B}, \phi_{N}^{F B}\right)$, if $q_{r}>\frac{1}{2}$, we can find a pair $(w, b)$ that implements $\left(\phi_{T}, \phi_{N}\right)$ if we neglect the constraint that $b$ must belong to $[0, \bar{b}]$.

Simple manipulations show that $b$ in (6) satisfies $b \leq \bar{b}$ if and only if

$$
\phi_{N}-\phi_{T} \geq \frac{\Pi_{T}-\Pi_{N}-\Delta p^{S}\left(2 q_{r}-1\right) \bar{b}+\alpha\left[\Delta p^{R}-\Delta p^{S}\left(2 q_{r}-1\right)\right]}{2 \gamma} .
$$

In order to interpret this condition, consider first the case without fame (i.e. $\alpha=0$ ). Then, under assumption 2 , the first best $\left(\phi_{T}^{F B}, \phi_{N}^{F B}\right)$ can never be implemented for any 
given $q_{r} \in\left[\frac{1}{2}, 1\right]$. In other words, for any $q_{r} \in\left[\frac{1}{2}, 1\right],(7)$ is violated at $\left(\phi_{T}, \phi_{N}\right)=$ $\left(\phi_{T}^{F B}, \phi_{N}^{F B}\right)$ since the monetary reward to talent in the private sector $\left(\Pi_{T}-\Pi_{N}\right)$ is larger than the maximal monetary reward to talent in science $\left(\Delta p^{S}\left(2 q_{r}-1\right) \bar{b}\right)$ on the one hand, and $\phi_{T}^{F B}>\phi_{N}^{F B}$ holds on the other hand. Furthermore, this argument also shows that no allocation satisfying $\phi_{T} \geq \phi_{N}$ is feasible when $\alpha=0$. Intuitively, given a cut-off type $\gamma_{N}$ for not-talented agents, it is impossible to induce a talented agent $i$ with $\gamma_{i} \geq \gamma_{N}$ to become a scientist because the monetary reward to talent in the private sector is larger than the one in science.

In the case of $\alpha>0$, instead, the non-pecuniary reward to talent in the private sector is equal to $\alpha \Delta p^{R}$, while the one in science is $\alpha\left(\beta_{T}-\beta_{N}\right)=\alpha \Delta p^{S}\left(2 q_{r}-1\right)$. From assumption 1 , when $q_{r}=1$, the latter is larger than the former. In contrast, when $q_{r}=\frac{1}{2}$, the latter is zero and thus smaller than the former. Therefore, there exists a threshold $\hat{q}_{r} \in\left(\frac{1}{2}, 1\right)$ such that the non-pecuniary reward to talent is larger in science than in the private sector if and only if the quality of the institution of science is higher than $\hat{q}_{r}$. Formally, $\left[\Delta p^{R}-\Delta p^{S}\left(2 q_{r}-1\right)\right]$ in (7) is negative if and only if $q_{r}>\hat{q}_{r}$. Then it is clear that, when $q_{r}>\hat{q}_{r}$, the first best can be achieved if $\alpha$ is sufficiently large because then the right hand side of (7) is negative enough and this makes (7) satisfied at $\left(\phi_{T}, \phi_{N}\right)=\left(\phi_{T}^{F B}, \phi_{N}^{F B}\right)$. In other words, if $q_{r}>\hat{q}_{r}$ and $\alpha$ is large, the first-best is implementable because the non-pecuniary reward to talent in science is much larger than the one in the private sector and outweighs the difference in the monetary rewards.

When the first-best allocation cannot be achieved, we find the second-best allocation of talent by solving the following program: ${ }^{18}$

$$
\max _{\left(\phi_{T}, \phi_{N}\right) \in[0,1]^{2}} S W \quad \text { subject to }(7)
$$

We denote the solution to (8) by $\left(\phi_{T}^{*}, \phi_{N}^{*}\right)$. The next proposition summarizes our results about the implementation of the first best and characterizes $\left(\phi_{T}^{*}, \phi_{N}^{*}\right)$.

Proposition 2 (incomplete information) Suppose that $\left(\theta_{i}, \gamma_{i}\right)$ is agent $i$ 's private information and that assumptions 1 to 3 are satisfied. Then

(i) The first best allocation $\left(\phi_{T}^{F B}, \phi_{N}^{F B}\right)$ is achievable if and only it satisfies (7), which occurs if and only if the institution of science is good enough $\left(q_{r}>\hat{q}_{r}\right)$ and the weight on fame $\alpha$ is sufficiently large. In particular, $\left(\phi_{T}^{F B}, \phi_{N}^{F B}\right)$ can never be implemented if $\alpha=0$.

\footnotetext{
${ }^{18}$ Since in the first best the inequality $b \leq \bar{b}$ is violated, we will find $b=\bar{b}$ in the second best; hence $b \geq 0$ is satisfied.
} 
(ii) If the first best allocation cannot be achieved, then the second best allocation of talent $\left(\phi_{T}^{*}, \phi_{N}^{*}\right)$ is characterized by

$$
\begin{gathered}
\phi_{T}^{*}=\phi_{T}^{F B}-\frac{\mu^{*}}{2 \nu \gamma}=\nu \phi_{T}^{F B}+(1-\nu) \phi_{N}^{F B}-(1-\nu) B, \\
\phi_{N}^{*}=\phi_{N}^{F B}+\frac{\mu^{*}}{2(1-\nu) \gamma}=\nu \phi_{T}^{F B}+(1-\nu) \phi_{N}^{F B}+\nu B,
\end{gathered}
$$

where $\mu^{*}=2 \nu(1-\nu) \gamma\left(B+\phi_{T}^{F B}-\phi_{T}^{F B}\right)>0$ is the multiplier associated with the constraint (7) and $B$ is the right hand side in (7). The second-best is such that

a. There is a brain drain from the science sector to the private sector: $\phi_{T}^{F B}>\phi_{T}^{*}$;

$b$. If $B>0$, which occurs if $\alpha$ is zero or small enough, then the fraction of not-talented agents becoming scientists is larger than that of talented agents: $\phi_{N}^{*}>\phi_{T}^{*}$

c. (comparative statics on the brain drain)

- As the quality of the institution of science increases, the brain drain decreases: $\frac{\partial\left(\phi_{T}^{F B}-\phi_{T}^{*}\right)}{\partial q_{r}}<0$

- As the weight on fame $\alpha$ increases, there is less (more) brain drain if the quality of the institution of science is higher (lower) than $\hat{q}_{r}: \frac{\partial\left(\phi_{T}^{F B}-\phi_{T}^{*}\right)}{\partial \alpha} \gtreqless 0$ if $q_{r} \lesseqgtr \hat{q}_{r}$.

Proposition 2 establishes that if $\alpha$ is small enough, the first best is not achievable, and then there is a brain drain from the science sector to the private sector in that the number of talented scientists is smaller in the second best than in the first-best outcome: $\phi_{T}^{*}<\phi_{T}^{F B}$. Figure 1 describes the first-best and the second-best allocations of talent in this case. As we have mentioned above, the brain drain is generated by assumption 2 , according to which the cap on the bonus in the science sector $\bar{b}$ makes the monetary reward to talent in the science sector smaller than the one in the private sector for any $q_{r}$. In addition, this gives talented agents larger incentives to become professionals than not-talented agents, which makes the fraction of scientists larger among not-talented agents than among talented agents: $\phi_{N}^{*}>\phi_{T}^{*}$.

$<$ "Figure 1: The first-best and the second-best allocations of talent in the absence of fame" should come here>

The institution of science has an important effect on the allocation of talent. A good institution of science improves the allocation and mitigates the brain drain by increasing both the monetary and non-monetary reward to talent in science. In particular, if the agents put sufficient weight $\alpha$ on fame, a good institution of science allows the government to achieve the first-best allocation. If the first-best cannot be attained, how $\alpha>0$ affects the brain drain depends on the quality of the institution of science. Specifically, if the quality of the institution of science is bad such that the non-pecuniary reward to talent in terms of fame is larger in the private sector than in the science sector, 
an increase in $\alpha$ makes choosing a professional career even more attractive to talented agents and therefore aggravates the brain drain. Thus, the existence of fame reduces the brain drain only if the quality of the institution is above a certain level. It is important to notice, however, that the results related to the effect of fame crucially depend on assumption 1. If that assumption is violated, then the non-pecuniary reward to talent is larger in the private sector than in science. As a result, the set of implementable allocations is reduced by the presence of fame (for any $q_{r}$ ) and, in particular, the first best is never achievable.

Our results suggest a possible explanation for the fact that, in the past, the western countries succeeded in inducing talented people to become scientists without giving large monetary returns to talent: building a good institution of science generated large nonpecuniary returns to talent in science that compensated for the lower monetary rewards to talent.

\section{Extra monetary rewards through the market and the allocation of talent}

Salary and bonus are not the only sources of income for scientists since they can generate revenue from consulting fees, patents, prizes and so on. In particular, in U.S., the BayhDole Act (1980) was introduced to foster interactions between academia and the business community: by enabling universities to claim ownership of the intellectual property rights generated from federally funded research, the Act provides scientists in academia with incentives to commercialize their inventions. Emulating the American experience, several member countries of OECD sought, beginning in the mid-1990s, to encourage commercialization of technology developed at universities.

In this section, we extend our model to study how the availability of extra monetary rewards through the market (in particular from licensing patents) affects scientists' research pattern and what its consequence is on brain drain (i.e. on the set of implementable allocations of talent) and on social welfare. One of the main concerns regarding the Bayh-Dole Act is that it can divert scientists' research from basic science to applied one (Cohen et al. 1998, Florida 1999, National Science Board 2004, Thursby and Thursby 2003). ${ }^{19}$ We focus on this aspect and consider a simple moral hazard problem;

\footnotetext{
${ }^{19}$ However, the empirical evidence is mixed. For instances, Cohen et al. (1998) provide evidence of countervailing effects of industry collaboration on faculty productivity in terms of publications while
} 
each scientist decides whether to divert some effort from basic to applied research. However, we depart from a simple linear relationship between basic and applied science and introduce what we call the Pasteur's Quadrant (PQ) coefficient, denoted by $y_{b}(>0),{ }^{20}$ to capture the fact that basic research can to some extent generate patentable scientific knowledge. Therefore, even though a scientist does not divert her effort, she can make extra money from the licensing opportunity. More precisely, if a type- $\theta$ scientist does not divert her effort, with probability $p_{\theta}^{S}$ she makes a path-breaking discovery, which generates an expected social benefit of $y_{b}$ from licensing in addition to $s^{H}{ }^{21}$ If there is diversion, her probability to make a path-breaking discovery decreases by $\Delta_{\theta}$ (with $p_{\theta}^{S}>\Delta_{\theta}>0$ and $\left.p_{T}^{S}-\Delta_{T}>p_{N}^{S}-\Delta_{N}\right)$ and the (expected) social benefit from licensing is equal to $\left(p_{\theta}^{S}-\Delta_{\theta}\right) y_{b}+\Delta_{\theta} y_{a}$ with $y_{a}>0$ (the subscript $a$ means applied science). We assume that a scientist captures a share $\delta \in(0,1]$ of the social value generated from licensing and that the government cannot make a scientist's salary depend on whether or not she diverts effort, as it is the case in reality.

We start by making the following assumption on $s^{H}-s^{L}$ :

Assumption 4: $\delta\left(s^{H}-s^{L}\right)>\bar{b}+\alpha$.

To explain assumption 4, suppose for the moment that $q_{r}=1$. In this case, if a scientist makes a path-breaking discovery instead of an ordinary one, social welfare increases by $s^{H}-s^{L}$ while her monetary payoff increases by $b \leq \bar{b}$ and her payoff from fame by $\alpha$. In general, the private return $(b+\alpha)$ from a great discovery induces a scientist to internalize only partially the social return $\left(s^{H}-s^{L}\right)$, which means that $s^{H}-s^{L}>b+\alpha$. Assumption 4 is stronger than this inequality and says that the private return is lower than the share $\delta$ of the social return.

We first analyze the private and social incentives to divert research and compare the two. Given $(w, b)$, the payoff of a type- $\theta$ scientist is $w+\delta p_{\theta}^{S} y_{b}+\beta_{\theta}(b+\alpha)$ if she does not divert her research and $w+\delta\left[\left(p_{\theta}^{S}-\Delta_{\theta}\right) y_{b}+\Delta_{\theta} y_{a}\right]+\left(\beta_{\theta}-\left(2 q_{r}-1\right) \Delta_{\theta}\right)(b+\alpha)$ otherwise. Therefore, regardless of her type, she diverts her research if and only if the

Thursby and Thursby (2003) find that licensing did not affect the portion of faculty's research that is published in basic journals.

${ }^{20}$ The subscript $b$ means basic science.

${ }^{21}$ Note that we assume that the market is efficient in that even when a path-breaking discovery is recognized as a low outcome, it generates $y_{b}$. This makes sense since although an important discovery is not published in a top journal, it can obtain a patent. 
PQ coefficient is lower than the threshold $y_{b}^{P}$ given by

$$
y_{b}^{P} \equiv \frac{\delta y_{a}-\left(2 q_{r}-1\right)(b+\alpha)}{\delta} .
$$

In what follows, for expositional simplicity, we assume $y_{b}^{P}>0$, which holds if $\delta y_{a}$ is large relative to $b+\alpha$, or if $q_{r}$ is close to $\frac{1}{2} \cdot{ }^{22}$

The social benefit generated by a type $\theta$ scientist is $p_{\theta}^{S}\left(s^{H}+y_{b}\right)+\left(1-p_{\theta}^{S}\right) s^{L}=S_{\theta}+p_{\theta}^{S} y_{b}$ if she fully dedicates herself to basic research and $\left(p_{\theta}^{S}-\Delta_{\theta}\right)\left(s^{H}+y_{b}\right)+\left(1-p_{\theta}^{S}+\Delta_{\theta}\right) s^{L}+$ $\Delta_{\theta} y_{a}=S_{\theta}+p_{\theta}^{S} y_{b}+\Delta_{\theta}\left(y_{a}-s^{H}+s^{L}-y_{b}\right)$ otherwise. Therefore, it is socially desirable that a scientist diverts her research if and only if the PQ coefficient is lower than the threshold $y_{b}^{S} \equiv y_{a}-\left(s^{H}-s^{L}\right)$, regardless of her type; ${ }^{23}$ notice that assumption 4 implies $y_{b}^{S}<y_{b}^{P}$. The first part of next proposition describes when the private and the social incentives of diverting research are aligned, and when they are not, given that the licensing opportunity exists. The second part considers a fixed allocation of talent and analyzes the social desirability of introducing the opportunity.

Proposition 3 Suppose that the government provides scientists with the opportunity to patent and license their findings. Suppose assumption 4 and $y_{b}^{P}>0$.

(i) (research pattern) We have two cases:

Case 1: when $y_{b} \geq y_{b}^{P}$. Providing the licensing opportunity does not affect scientists' research pattern and no change in research pattern is socially desirable.

Case 2: when $y_{b} \in\left(0, y_{b}^{P}\right)$. Providing the licensing opportunity induces scientists to divert part of their attention from basic to applied science. If $y_{b}^{S}>0$ and $y_{b} \in\left(0, y_{b}^{S}\right)$, this change is socially beneficial; otherwise (i.e. if $y_{b} \in\left(y_{b}^{S}, y_{b}^{P}\right)$ ), the change is socially detrimental.

(ii) (desirability of Bayh-Dole Act for a given allocation of talent)

a. Providing the licensing opportunity always increases social welfare in case 1. In contrast, in case 2, it increases social welfare when

$$
y_{b}^{S} \geq 0, \quad \text { or } \quad y_{b}^{S}<0 \quad \text { and } \quad y_{b}>\frac{\Delta_{\theta}}{p_{\theta}^{S}-\Delta_{\theta}}\left|y_{b}^{S}\right| \quad \text { for } \quad \theta=T, N ;
$$

it decreases social welfare when

$$
y_{b}^{S}<0 \quad \text { and } \quad y_{b}<\frac{\Delta_{\theta}}{p_{\theta}^{S}-\Delta_{\theta}}\left|y_{b}^{S}\right| \quad \text { for } \quad \theta=T, N .
$$

\footnotetext{
${ }^{22}$ The restriction to $y_{b}^{P}>0$ allows us to reduce the number of cases and actually leaves us with the most interesting cases. Indeed, if $y_{b}^{P} \leq 0$ then $y_{b} \geq y_{b}^{P}$ is satisfied and we are always in case 1 (in the terminology of Propositions 3 and 4 below).

${ }^{23}$ In particular, diverting research is never socially optimal if $s^{H}>s^{L}+y_{a}$ since this implies $y_{b}^{S}<0$.
} 
b. As the institution of science improves, $y_{b}^{P}$ decreases, and therefore it is more likely that providing the licensing opportunity increases social welfare.

Proposition 3(i) reveals the importance of the PQ coefficient $y_{b}$ in determining the impact of the licensing opportunity on the research pattern. In particular, it shows that if the coefficient is smaller than $y_{b}^{P}$, then the licensing opportunity can create a conflict since it leads scientists to divert research from basic to applied science even though this may be socially undesirable. As a consequence of the conflict, for a fixed allocation of talent, proposition 3(ii)a states that providing the opportunity decreases social welfare (with respect to not introducing the opportunity) for low values of $y_{b}$, if $s^{H}-s^{L}>y_{a}$. Even though we do not model different research fields, in reality the value of $y_{b}$ should depend on the field: for instance, it should be high for life science and engineering and low for physics and astronomy. Finally, an increase in the quality of the institution decreases $y_{b}^{P}$, which in turn enlarges the zone of case 1 in which there is no conflict between private and social incentives. Therefore, the licensing opportunity is more likely to increase social welfare the better the institution of science is because it makes it less likely that scientists will divert their research.

Proposition 3(ii) about the social desirability of the Bayh-Dole Act applies for a given allocation of talent, but it is clear that the licensing opportunity also affects the allocation of talent through the monetary and non-monetary reward to talent. In order to examine this effect of the Act, we suppose from now on that before the licensing opportunity is available, the constraint $b \leq \bar{b}$ binds and generates a brain drain as described in subsection 3.2. We say that the licensing opportunity reduces (worsens) the brain drain if it enlarges (reduces) the set of implementable allocations of talent. Let $\bar{y}_{b}^{P} \equiv y_{a}-\frac{1}{\delta}\left(2 q_{r}-1\right)(\bar{b}+\alpha)$ be the value of $y_{b}^{P}$ when $b=\bar{b}$. We have

Proposition 4 (brain drain) Suppose that the government provides scientists with the opportunity to patent and license their research in a setting characterized by brain drain.

(i) We have two cases:

Case 1: when $y_{b} \geq \bar{y}_{b}^{P}$. Providing the opportunity reduces the brain drain.

Case 2: when $y_{b} \in\left(0, \bar{y}_{b}^{P}\right)$.

a. When talented scientists divert research more than not-talented scientists do $\left(\Delta_{T} \geq \Delta_{N}\right)$; providing the licensing opportunity reduces the brain drain.

b. When talented scientists divert research less than not-talented scientists do $\left(\Delta_{T}<\right.$ $\left.\Delta_{N}\right)$; there is a threshold $\hat{y}_{b}\left(<\bar{y}_{b}^{P}\right)$ such that providing the opportunity reduces (worsens) 
the brain drain if $y_{b}>\hat{y}_{b}$ (if $\left.y_{b}<\hat{y}_{b}\right)$, where

$$
\hat{y}_{b} \equiv \bar{y}_{b}^{P} \frac{\Delta_{N}-\Delta_{T}}{\Delta p^{S}+\Delta_{N}-\Delta_{T}} .
$$

(ii) As the institution of science improves, both $\hat{y}_{b}$ and $\bar{y}_{b}^{P}$ decrease; thus providing the licensing opportunity is more likely to reduce the brain drain.

Providing the licensing opportunity reduces (worsens) the brain drain if it increases (decreases) the reward to talent in science. When the PQ coefficient is high (i.e. case 1), providing the opportunity reduces the brain drain since there is no change in research pattern and a talented scientist's expected income from licensing is higher than that of a not-talented one by $\delta \Delta p^{S} y_{b}>0$.

When the PQ coefficient is low (i.e. case 2), there is a change in the research pattern that affects the reward to talent in science through two channels. First, there is a direct effect from licensing income. Type $\theta$ earns a licensing income equal to $\delta\left[\left(p_{\theta}^{S}-\Delta_{\theta}\right) y_{b}+\right.$ $\left.\Delta_{\theta} y_{a}\right]$, originated from basic and applied research. Thus, the monetary reward to talent varies by $\delta\left[\Delta p^{S} y_{b}+\left(\Delta_{T}-\Delta_{N}\right)\left(y_{a}-y_{b}\right)\right]$; in particular, since $y_{a}>y_{b}$ holds in case 2 , the monetary reward to talent increases if $\Delta_{T} \geq \Delta_{N}$. Second, there is an indirect effect since the change in research pattern affects the information structure in science. For instance, if $\Delta_{T}>\Delta_{N}$ holds, this makes the intrinsic outcome of science a noisier signal of talent and thereby reduces the reward to talent provided by the institution of science by $\left(2 q_{r}-1\right)\left(\Delta_{T}-\Delta_{N}\right)(\bar{b}+\alpha)$. Therefore, the total effect on the reward to talent in science is given by

$$
\begin{aligned}
& \delta \Delta p^{S} y_{b}+\left(\Delta_{T}-\Delta_{N}\right)\left[\delta\left(y_{a}-y_{b}\right)-\left(2 q_{r}-1\right)(\bar{b}+\alpha)\right] \\
= & \delta\left[\Delta p^{S} y_{b}+\left(\Delta_{T}-\Delta_{N}\right)\left(\bar{y}_{b}^{P}-y_{b}\right)\right] .
\end{aligned}
$$

Since $\bar{y}_{b}^{P}>y_{b}$ in case 2 and $\Delta p^{S} y_{b}>0$, we see that providing the licensing opportunity always reduces the brain drain when $\Delta_{T} \geq \Delta_{N}$. In contrast, if $\Delta_{T}<\Delta_{N}$ holds, then the change in the reward to talent is $\left(\Delta_{T}-\Delta_{N}\right) \bar{y}_{b}^{P}<0$ if $y_{b}=0$ but is increasing with $y_{b}$ since $\Delta p^{S}>\Delta_{T}-\Delta_{N}$. Thus, there is a threshold $\hat{y}_{b}$ such that the availability of licensing opportunity worsens the brain drain if and only if $y_{b}<\hat{y}_{b}$.

We think that the availability of licensing opportunity is likely to reduce the brain drain since $\Delta_{T} \geq \Delta_{N}$ seems to be more probable than $\Delta_{T}<\Delta_{N}$. For instance, if both types divert the same amount of time to applied research and this reduces their probabilities of success by the same fraction, then $\Delta_{T}>\Delta_{N}$ follows from $p_{T}^{S}>p_{N}^{S}$. Alternatively, it is reasonable to think that $p_{N}^{S}$ is quite small and close to zero while 
$p_{T}^{S}$ is substantially larger; thus it is plausible that $\Delta_{T}$ is larger than $p_{N}^{S}\left(\geq \Delta_{N}\right) \simeq 0$. However, we stress that even though the brain drain decreases, a large reduction of talented agents' productivity in pure research can be socially harmful, especially if $s^{H}$ is much larger than $s^{L}$; see proposition 3(ii)a and its proof.

Finally, since an increase in the quality of the institution of science decreases both $\bar{y}_{b}^{P}$ and $\hat{y}_{b}$, we conclude that providing the licensing opportunity is more likely to reduce the brain drain when the institution of science is good.

In order to evaluate the global effect of the licensing opportunity on social welfare, we observe that social welfare definitely increases (decreases) if social welfare increases (decreases) for any given allocation and the availability of the licensing opportunity enlarges (reduces) the set of implementable allocations. Therefore, the following corollary results from Propositions 3 and 4.

Corollary 1 Suppose that the licensing opportunity is introduced in a setting with a brain drain. Then

(i) it increases social welfare when $y_{b} \geq \bar{y}_{b}^{P}$ or when $\hat{y}_{b}<y_{b}<\bar{y}_{b}^{P}$ and (10) is satisfied. It decreases social welfare when $y_{b}<\hat{y}_{b}$ and (11) is satisfied;

(ii) it is more likely to increase social welfare when the institution of science is good.

Although this corollary does not cover all the parameter values, the main insight is clear. First, introducing the licensing opportunity improves social welfare if the PQ coefficient is sufficiently large, while it may decrease social welfare if the coefficient is small enough. Second, a good institution of science makes introducing the licensing opportunity more likely to be welfare-enhancing.

\section{Optimal balance between monetary and non-monetary rewards in science}

In this section we consider a general setting in which the government, in addition to paying wages to scientists, distributes research grants. The grants affect a scientist's non-monetary reward by affecting her probability to make a path-breaking discovery. Furthermore, we drop assumptions 1-3 and assume away any constraint on wages such as the cap on bonus $\bar{b}$ we considered in the previous sections. As we explain later in the section, this implies that any given allocation can be implemented by the government with a suitable wage structure, and therefore there is no issue of brain drain in this 
section. In this general setting, we study two following problems: we first investigate the optimal balance between the monetary and non-monetary rewards in science and how the balance should vary depending on parameters such as the quality of the institution of science; second, we compare the monetary reward to talent in science with the one in the private sector. In particular, we show the optimality of relatively flat wages in science. For this purpose, we enrich the basic model in three respects.

First, after each agent makes her occupational choice, for each scientist $i$, the government observes a signal $\sigma_{i}$ which is positively correlated with $\theta_{i}$ but is not correlated with $\theta_{j}$ for any $j \neq i$. The signal can be either good or bad: $\sigma_{i} \in\{G, B\}$. For instance, $\sigma_{i}$ represents scientist $i$ 's performance in the early stages of her career. Let $q_{s} \in\left(\frac{1}{2}, 1\right]$ represent the quality, or precision, of the signal in the following sense:

$$
q_{s} \equiv \operatorname{Pr}\left\{\sigma_{i}=G \mid \theta_{i}=T\right\}=\operatorname{Pr}\left\{\sigma_{i}=B \mid \theta_{i}=N\right\}
$$

For simplicity, however, we assume that recognition depends only on the (final) perceived outcome and not on the early signal.

Second, the government allocates research grants to scientist $i$ on the basis of $\sigma_{i}$; let $g_{G}\left(g_{B}\right)$ represent the research grant given to scientist $i$ when $\sigma_{i}=G$ (when $\sigma_{i}=B$ ). A scientist's probability of making a path-breaking discovery depends both on her talent and on her research grant. More precisely, let $p_{\theta}^{S}(g)$ represent the probability for a type- $\theta$ scientist to make a path-breaking discovery when she receives grant $g$. Assumption 5 below specifies the properties of the functions $p_{T}^{S}(g)$ and $p_{N}^{S}(g)$.

Last, we introduce a positive shadow cost of public funds $\lambda>0$, meaning that each dollar spent by the government is raised through distortionary taxes (labor, capital and commodity taxes) and costs society $1+\lambda$ dollars (Laffont and Tirole 1993). In the case of $\lambda=0$, neither $\alpha$ nor $q_{r}$ has any impact on the optimal balance between the monetary and non-monetary rewards since the government can costlessly replicate any non-monetary reward in science through wages, which are pure transfers. When $\lambda>0$, instead, a trade-off exists between monetary and non-monetary rewards.

We suppose that $s^{H}-s^{L}>\alpha,{ }^{24}$ and make the following assumption regarding $p_{T}^{S}(g)$ and $p_{N}^{S}(g)$ :

Assumption 5: (i) $p_{T}^{S}(0) \geq p_{N}^{S}(0)$ and $\frac{d p_{T}^{S}}{d g} \geq \frac{d p_{N}^{S}}{d g} \geq 0$ for any $g>0$; $\frac{d p_{N}^{S}(0)}{d g}>\frac{1+\lambda}{s^{H}-s^{L}}$; (ii) $0>\frac{d^{2} p_{T}^{S}}{d g^{2}}>\frac{d^{2} p_{N}^{S}}{d g^{2}}$ whenever $\frac{d p_{N}^{S}}{d g}>0$.

\footnotetext{
${ }^{24}$ This condition is weaker than assumption 4 and was explained when assumption 4 was introduced.
} 
The first part of the assumption says that the marginal productivity of grants is positive and is larger for a talented scientist than for a not-talented scientist; the assumption on $\frac{d p_{N}^{S}(0)}{d g}$ implies that the optimal $g$ is strictly positive for both signals. The second part says that the marginal productivity decreases and it does so faster for a not-talented scientist than for a talented scientist.

In what follows, we proceed in two steps. First, we fix an allocation of talent $\left(\phi_{T}, \phi_{N}\right)$ that the government wants to achieve and study the optimal balance between monetary and non-monetary rewards and how this balance is affected by a change in parameters $\alpha, q_{r}, \lambda$. Second, we characterize the optimal allocation of talent.

Let $m_{\theta}^{e}$ represent the expected monetary payoff for a type $\theta$ scientist. Since $q_{s}>\frac{1}{2}$ and there is no constraint on the wage schedule, the arguments given at the beginning of subsection 3.2 show that any pair $\left(m_{T}^{e}, m_{N}^{e}\right)$ is attainable by the government. Specifically, the government may choose (for instance) a wage schedule with a fixed term plus a bonus linked to the signal $\sigma_{i}{ }^{25}$

As in the previous sections, $\beta_{\theta}$ is the probability for a type $\theta$ scientist to get a high perceived outcome. It is now given by

$$
\begin{aligned}
& \beta_{T} \equiv\left[q_{s} p_{T}^{S}\left(g_{G}\right)+\left(1-q_{s}\right) p_{T}^{S}\left(g_{B}\right)\right] q_{r}+\left[1-\left(q_{s} p_{T}^{S}\left(g_{G}\right)+\left(1-q_{s}\right) p_{T}^{S}\left(g_{B}\right)\right)\right]\left(1-q_{r}\right) \\
& \beta_{N} \equiv\left[q_{s} p_{N}^{S}\left(g_{B}\right)+\left(1-q_{s}\right) p_{N}^{S}\left(g_{G}\right)\right] q_{r}+\left[1-\left(q_{s} p_{N}^{S}\left(g_{B}\right)+\left(1-q_{s}\right) p_{N}^{S}\left(g_{G}\right)\right)\right]\left(1-q_{r}\right) .
\end{aligned}
$$

Arguing as in subsection 3.2, we find that in order to implement a given (interior) allocation $\left(\phi_{T}, \phi_{N}\right)$, it is necessary and sufficient that $\left(m_{T}^{e}, m_{N}^{e}, g_{G}, g_{B}\right)$ satisfy the following incentive constraints:

$$
\begin{aligned}
\left(I C_{T}\right) \quad \Pi_{T}+2 \gamma \phi_{T}-\gamma+\alpha p_{T}^{R} & =m_{T}^{e}+\alpha \beta_{T} \\
\left(I C_{N}\right) & \Pi_{N}+2 \gamma \phi_{N}-\gamma+\alpha p_{N}^{R}=m_{N}^{e}+\alpha \beta_{N} .
\end{aligned}
$$

Note first that the left hand side of $\left(I C_{\theta}\right)$ represents the reservation utility of a type- $\theta$ scientist having $\gamma_{i}=2 \gamma \phi_{\theta}-\gamma$. Given an allocation of talent, this reservation utility is fixed. Therefore, an increase in $g_{G}$ or $g_{B}$ increases the non-pecuniary rewards to both types of scientist through an increase in the probability to make a path-breaking discovery, and this in turn decreases the monetary rewards $m_{T}^{e}$ and $m_{N}^{e}$ by (14)-(15).

Since $\left(\phi_{T}, \phi_{N}\right)$ is given, the contribution to social welfare generated by the private sector is constant and the objective of the government is the social welfare generated by science minus the social cost of salaries and grants. We denote this objective by $S W^{S}$

\footnotetext{
${ }^{25}$ This schedule is similar to the one of subsection 3.2 , but the bonus is obtained when $\sigma_{i}=G$.
} 
and let $S_{\theta}(g) \equiv p_{\theta}^{S}(g) s^{H}+\left(1-p_{\theta}^{S}(g)\right) s^{L}$ for $\theta \in\{N, T\}$ represent the expected social surplus generated by a type $\theta$ scientist who receives grant $g$. Then, we have

$$
\begin{aligned}
S W^{S}= & q_{s}\left\{\nu \phi_{T}\left[S_{T}\left(g_{G}\right)-(1+\lambda) g_{G}\right]+(1-\nu) \phi_{N}\left[S_{N}\left(g_{B}\right)-(1+\lambda) g_{B}\right]\right\} \\
& +\left(1-q_{s}\right)\left\{\nu \phi_{T}\left[S_{T}\left(g_{B}\right)-(1+\lambda) g_{B}\right]+(1-\nu) \phi_{N}\left[S_{N}\left(g_{G}\right)-(1+\lambda) g_{G}\right]\right\} \\
& -\lambda\left[\nu \phi_{T} m_{T}^{e}+(1-\nu) \phi_{N} m_{N}^{e}\right] .
\end{aligned}
$$

We can express $m_{T}^{e}$ and $m_{N}^{e}$ as functions of $\left(g_{G}, g_{B}\right)$ from (14) and (15) and insert them into $S W^{S}$. We obtain a (concave) function of $\left(g_{G}, g_{B}\right)$, and therefore the following first-order conditions are necessary and sufficient for maximization: ${ }^{26}$

$$
\begin{aligned}
& \nu \phi_{T} q_{s}\left(\frac{d p_{T}^{S}\left(g_{G}\right)}{d g_{G}}-k\right)+(1-\nu) \phi_{N}\left(1-q_{s}\right)\left(\frac{d p_{N}^{S}\left(g_{G}\right)}{d g_{G}}-k\right)=0 \\
& \nu \phi_{T}\left(1-q_{s}\right)\left(\frac{d p_{T}^{S}\left(g_{B}\right)}{d g_{B}}-k\right)+(1-\nu) \phi_{N} q_{s}\left(\frac{d p_{N}^{S}\left(g_{B}\right)}{d g_{B}}-k\right)=0 ;
\end{aligned}
$$

where

$$
k \equiv \frac{1+\lambda}{s^{H}-s^{L}+\alpha \lambda\left(2 q_{r}-1\right)} .
$$

We below give an economic interpretation of $k$ through the special case of perfect correlation between $\sigma_{i}$ and $\theta_{i}$ (i.e. $q_{s}=1$ ). Then, we find

$$
\frac{d p_{T}^{S}\left(g_{G}\right)}{d g_{G}}=k=\frac{d p_{N}^{S}\left(g_{B}\right)}{d g_{B}} .
$$

Consider a unitary increase in $g_{G}$, for instance. On the one hand, the social marginal cost of providing a unit of grant is $1+\lambda$. On the other hand, there are two social marginal benefits. One is the direct social benefit from an increased probability of having the path-breaking discovery, which is equal to $\frac{d p_{T}^{S}\left(g_{G}\right)}{d g_{G}}\left(s^{H}-s^{L}\right)$. The other is the indirect social benefit related to the fact that the increase in the non-monetary reward in terms of fame allows the government to reduce the monetary reward necessary to achieve the given allocation of talent, which is equal to $\frac{d p_{T}^{S}\left(g_{G}\right)}{d g_{G}} \alpha \lambda\left(2 q_{r}-1\right)$. Therefore, the total social marginal benefit is $\frac{d p_{T}^{S}\left(g_{G}\right)}{d g_{G}}\left[s^{H}-s^{L}+\alpha \lambda\left(2 q_{r}-1\right)\right]$. Observe that the numerator of $k$ is the social marginal cost of grants while the denominator represents the social marginal benefit from an increase in $p_{T}^{S}$. Therefore, we call $k$ the benefit-adjusted social marginal cost of providing grants. In the extreme case of $\lambda=0, k$ is independent from $\alpha$ and $q_{r}$.

\footnotetext{
${ }^{26}$ We have $g_{G}>0$ and $g_{B}>0$ in the optimum because of assumption 5(i). Furthermore, a unique solution to (16)-(17) exists because $\frac{d p_{T}^{S}}{d g}$ and $\frac{d p_{N}^{S}}{d g}$ are strictly decreasing and $\frac{d p_{\theta}^{S}(g)}{d g} \rightarrow 0$ as $g \rightarrow+\infty$ (by assumption 5(ii)).
} 
In this case, non-monetary rewards in science have no role since the government can use costless monetary transfers (salaries and bonuses) to replicate any non-monetary reward; therefore, the optimal research grants are determined by simply equalizing the direct social benefit from grants and the social cost of grants. Let $\left(g_{G}^{*}\left(\alpha, q_{r}, \lambda\right), g_{B}^{*}\left(\alpha, q_{r}, \lambda\right)\right)$ denote the optimal grants and $\left(m_{T}^{e *}\left(\alpha, q_{r}, \lambda\right), m_{N}^{e *}\left(\alpha, q_{r}, \lambda\right)\right)$ the optimal expected salaries. We have the following proposition:

Proposition 5 (optimal monetary and non-monetary rewards) Suppose that $\left(\theta_{i}, \gamma_{i}\right)$ is agent $i$ 's private information and that $s^{H}-s^{L}>\alpha$. Under assumption 5 and given an allocation of talent $\left(\phi_{T}, \phi_{N}\right) \in(0,1)^{2}$ that the government wants to implement,

(i) The optimal monetary and non-monetary rewards $\left(g_{G}^{*}, g_{B}^{*}, m_{T}^{e *}, m_{N}^{e *}\right)$ are characterized through $k$, the benefit-adjusted social marginal cost of providing grants, by (14)-(17).

(ii) (comparative statics)

a. (balance between the two rewards) Both grants $g_{G}^{*}$ and $g_{B}^{*}$ decrease with $k$ and therefore the monetary rewards to both types $m_{T}^{e *}$ and $m_{N}^{e *}$ increase with $k$;

$b . \quad k$ is decreasing with respect to the weight on fame $\alpha$ and the quality of the institution of science $q_{r} ; k$ is increasing with respect to the shadow cost of public funds $\lambda$.

The optimal balance between monetary and non-monetary rewards is characterized through $k$, the benefit-adjusted social marginal cost. By (16)-(17), an increase in $k$ reduces both grants (hence, the non-monetary rewards for both types), which in turn increases, from (14) and (15), the monetary rewards for both types. Proposition 5(ii) shows how each parameter affects this balance through $k$. An increase in the weight on fame $\alpha$, an increase in the quality of the institution of science $q_{r}$, and a decrease in the shadow cost of public funds $\lambda$ all shift the balance from monetary reward to nonmonetary reward by decreasing $k$. To understand how a change in $\lambda$ affects the balance, note that as $\lambda$ increases, both the total social benefits from grants $s^{H}-s^{L}+\alpha \lambda\left(2 q_{r}-1\right)$ and the social cost of grants $1+\lambda$ increase. However, since a scientist does not fully internalize the social benefit from a path-breaking research (i.e. $s^{H}-s^{L}>\alpha$ ), we have $s^{H}-s^{L}>\alpha\left(2 q_{r}-1\right)$. This implies that the increase in the total benefits is relatively smaller than the increase in the cost and therefore $k$ increases with $\lambda$. Hence, as $\lambda$ increases, it is optimal to decrease grants while increasing salaries.

Now we compare the monetary reward to talent in science with the one in the private sector. Since the mapping between the talent and the outcome is endogenous through the choice of grants, we introduce a modified version of assumption 1 as follows. Define $\underline{g}$ by $\frac{d p_{N}^{S}(\underline{g})}{d g}=\frac{1+\lambda}{s^{H}-s^{L}}$. Then, we have $g_{G}^{*}\left(\alpha, q_{r}, \lambda\right)>g_{B}^{*}\left(\alpha, q_{r}, \lambda\right) \geq \underline{g}>0$ for all $\left(\alpha, q_{r}, \lambda\right)$. 
Assumption 1': $\Delta \underline{p}^{S} \equiv p_{T}^{S}(\underline{g})-p_{N}^{S}(\underline{g})>\Delta p^{R}$.

This assumption is a sufficient condition to make the intrinsic outcome a less noisy signal of talent in science than in the private sector when grants are chosen optimally, for any $\left(\alpha, q_{r}, \lambda\right)$. From (14)-(15), the difference between the monetary reward to talent in the private sector $\left(\Pi_{T}-\Pi_{N}\right)$ and the one in science $\left(m_{T}^{e *}-m_{N}^{e *}\right)$ is given by

$$
\alpha\left[\left(\beta_{T}-\beta_{N}\right)-\Delta p^{R}\right]-2 \gamma\left(\phi_{T}-\phi_{N}\right) .
$$

We now give sufficient conditions for the optimality of lower monetary rewards to talent in science than in the private sector.

Proposition 6 (relatively flat monetary rewards in science) Suppose that $\left(\theta_{i}, \gamma_{i}\right)$ is agent $i$ 's private information and that assumptions 1' and 5 are satisfied. Given an allocation of talent $\left(\phi_{T}, \phi_{N}\right) \in(0,1)^{2}$ that the government wants to achieve, the monetary reward to talent in science is lower than the one in the private sector if $\phi_{T} \leq \phi_{N}+\Phi$, with $\Phi \equiv \frac{\alpha}{2 \gamma}\left[\left(2 q_{r}-1\right) \Delta \underline{p}^{S}-\Delta p^{R}\right]$; thus, $\Phi>0$ if $q_{r}>\underline{q}_{r} \equiv\left(\Delta \underline{p}^{S}+\Delta p^{R}\right) / 2 \Delta \underline{p}^{S}>\frac{1}{2}$.

Proposition 6 says that the optimal incentive structure is such that the monetary reward to talent in the science sector is lower than the one in the private sector for all allocations satisfying $\phi_{T} \leq \phi_{N}+\Phi$, where $\Phi>0$ if the quality of the institution of science is good enough (i.e. $q_{r}>\underline{q}_{r}$ ). Moreover, $\Phi$ is (linearly) increasing with respect to $\alpha$ if $q_{r}>\underline{q}_{r}$. Therefore, the monetary reward to talent should be lower in science than in the private sector for any allocation $\left(\phi_{T}, \phi_{N}\right)$ if $\alpha$ is large enough and $q_{r}>\underline{q}_{r}$. Hence, proposition 6 provides one possible rationale for the commonly observed relatively flat wages in science. The insight here is similar to the one in section 3.2: the science sector can provide a high non-monetary reward to talent given that the intrinsic outcome is a less noisy signal of talent in science than in the private sector.

We now study the optimal allocation of talent. Given that salaries and grants are chosen optimally, as described above, the social welfare is given by

$$
\begin{aligned}
S W\left(\phi_{T}, \phi_{N}\right)= & \nu\left(1-\phi_{T}\right) \Pi_{T}+(1-\nu)\left(1-\phi_{N}\right) \Pi_{N}+\gamma\left[\nu \phi_{T}\left(1-\phi_{T}\right)+(1-\nu) \phi_{N}\left(1-\phi_{N}\right)\right] \\
& +S W^{S}\left(\phi_{T}, \phi_{N}, g_{G}^{*}\left(\phi_{T}, \phi_{N}\right), g_{B}^{*}\left(\phi_{T}, \phi_{N}\right)\right) .
\end{aligned}
$$

Using the envelope theorem, we find the first order conditions for an interior maximum):

$$
\begin{aligned}
\Pi_{T}+\gamma\left(2 \phi_{T}-1\right) & =q_{s}\left[S_{T}\left(g_{G}^{*}\right)-(1+\lambda) g_{G}^{*}\right]+\left(1-q_{s}\right)\left[S_{T}\left(g_{B}^{*}\right)-(1+\lambda) g_{B}^{*}\right]-\lambda\left(m_{T}^{e *}+2 \gamma \phi_{T}\right) \\
\Pi_{N}+\gamma\left(2 \phi_{N}-1\right) & =q_{s}\left[S_{N}\left(g_{B}^{*}\right)-(1+\lambda) g_{B}^{*}\right]+\left(1-q_{s}\right)\left[S_{N}\left(g_{G}^{*}\right)-(1+\lambda) g_{G}^{*}\right]-\lambda\left(m_{N}^{e *}+2 \gamma \phi_{N}\right) .
\end{aligned}
$$


The left hand side represents the social gain that the marginal agent who is indifferent between the two professions produces as a professional while the right hand side represents the social gain that she produces as a scientist. The right hand side is composed of the social gain from research minus the social cost of grants and wages: the last term $m_{\theta}^{e *}+2 \gamma \phi_{\theta}$ is equal to $\frac{\partial\left(\phi_{\theta} m_{\theta}^{e *}\right)}{\partial \phi_{\theta}}$, which is the increase in the wage bill $\phi_{\theta} m_{\theta}^{e *}$ induced by a marginal increase in $\phi_{\theta}$.

\section{Concluding remarks}

The earning structure in science is known to be flat relative to the one in the private sector, and this raises concerns about the brain drain from the science sector to the private sector. This paper points out that since performance is a less noisy signal of talent in the science sector than in the private sector, if agents care about both money and peer recognition, a good institution of science can mitigate the brain drain by providing a high non-pecuniary reward to talent. Furthermore, when the institution of science is good and scientists care a lot about priority recognition, a relatively flat earning structure in science is likely to be optimal. Despite the desirability of providing strong monetary and non-monetary incentives to scientists, one should be cautious with introducing extra monetary incentives through the market by encouraging research for commercialization. For instance, the extra incentives can induce too much shift from basic to applied research and thereby result in a lower social welfare.

Our results suggest that the current increase in team size in science ${ }^{27}$ might have a negative consequence in terms of the brain drain. For instance, in an experimental article in physics, the author list can be longer than the article and in such a case the role of the individual scientist is hard to evaluate. In fact, Merton (1968) argues that the growth of team work makes the recognition of individual contributions by others problematic.

It would be interesting to study how recognition from non-peers affects the allocation of talent. In general, outsiders would have difficulty telling whether a professor has a good or bad publication record, but it would be easy for them to know about the institution to which a professor belongs. Since non-peers would give more recognition to professors of prestigious universities than to professors of mediocre universities, and becoming professor of a prestigious university would generally require talent, a hierarchical organization of universities as in the U.S. could increase the reward to talent in terms of

\footnotetext{
${ }^{27}$ Adams et al. find that team size increased by 50 percent in the U.S. over the period 1981-1999.
} 
non-peer recognition and hence mitigate the brain drain. In contrast, in (Continental) Europe, most universities are local monopolies and therefore there is not much quality differentiation among them.

If all agents highly value autonomy or freedom in academia, this should make wages in academia lower than the one in the private sector as in Aghion et al. (2005). Although this can be easily captured in our model with a negative mean value of $\gamma_{i}$ for both types of agents, we would like to emphasize that our focus is not about the absolute wage differential between the two sectors but about the relatively flat monetary reward to talent in science.

In reality, the intrinsic pleasure from being a scientist (such as the pleasure from solving puzzles) may be positively correlated with talent, implying that the mean value of $\gamma_{i}$ conditional on $\theta_{i}=T$ is smaller than the one conditional on $\theta_{i}=N$ in our setting. We find that in this case, compared to the case of no correlation, the set of implementable allocations of talent expands, but the first-best allocation has a higher $\phi_{T}^{F B}$ and a lower $\phi_{N}^{F B}$ such that the first-best cannot be implemented under incomplete information in the absence of fame as long as the earning structure is flatter in science than in the private sector. Furthermore, an explanation entirely based on the positive correlation cannot shed any light on the role of the institution of science as a mechanism distributing priority recognition emphasized by Merton.

In our model, the public sector is active while the private sector is passive in that the government actively induces talented agents to become scientists while taking their outside options in the private sector as given. However, in reality, things can be more complex since the private sector is at least as much interested in attracting talented people as the government is, and therefore the government's attempt to attract talented people might induce the private sector to bid up their wages.

Finally, the various benefits from having a good institution of science that this paper identified suggest that the government might intervene to improve the institution. Regarding the intervention of the government, we can distinguish two different dimensions: the intervention in the certification (i.e. referring) process and the intervention to improve dissemination of knowledge. On the one hand, we did not consider the possibility for the government to improve the certification process, which seems to be a delicate issue. Since academia enjoys a substantial degree of autonomy (at least in western countries), it seems difficult for the government to find ways to improve the accuracy of refereeing. ${ }^{28}$ Therefore, we restricted the government to perform only its most tradi-

\footnotetext{
${ }^{28}$ However, we admit that the design of optimal incentives for refereeing is a very interesting issue for
} 
tional role of paying wages and allocating research funds. On the other hand, electronic publishing seems to offer new opportunities to improve dissemination of scientific knowledge. For instance, the recent report on the market for academic journals commissioned by European Commission (2006) recommends the creation of an open access repository in Europe and the experimentation of open access journals. However, there exist concerns that private interests of commercial publishers having market power might be in conflict with the realization of the potential gain from the electronic publishing. ${ }^{29}$

\section{References}

Acemoglu, D., Verdier, T., 1998. Property rights, corruption and the allocation of talent: a general equilibrium approach. Economic Journal 108, 1381-403.

Acemoglu, D., Verdier, T., 2000. The choice between market failures and corruption. American Economic Review 90, 194-211.

Adams, J.D., Black, G.C., Clemmons, J.R., Stephan, P.E., 2005. Scientific teams and institutional collaborations: evidence from U.S. universities, 1981-1999. Research Policy 34, 259-285.

Aghion, P., Cohen, E., 2004. Éducation et Croissance. Paris: La Documentation Française.

Aghion, P., Dewatripont, P., Stein, J.C., 2005. Academic freedom, private-sector focus, and the process of innovation. NBER Working Paper 11542.

Benabou, R., Tirole, J., 2006. Incentives and prosocial behavior. American Economic Review 96, 1652-1678.

Besley, T., Ghatak, M., 2005. Competition and incentives with motivated agents. American Economic Review 95, 616-636.

Butz, W., Bloom, G., Gross, M., Kelly, K., Kofner, A., Rippen, H., 2003. Is there a shortage of scientists and engineers? How would we know? Rand Issue Paper 241.

Caselli, F., 1999. Technological revolutions. American Economic Review 89, 78-102.

Cohen, W., Florida, R., Randazzese, L., Walsh, J., 1998. Industry and the academy: uneasy partners in the cause of technological advance. In: Noll, R. (Ed.). Challenges to Research Universities. Washington, D.C.: Brookings Institution Press, 171-199.

future research.

${ }^{29}$ For instance, big commercial publishers' bundling practices can force the libraries to spend too much money on their journals, which leaves little money for small publishers and builds entry barriers (Edlin and Rubinfeld 2004, Jeon and Menicucci 2006). 
Dasgupta, P., David, P.A., 1987. Information disclosure and the economics of science and technology. In: Feiwel, G.R. (Ed.). Arrow and the Ascent of Modern Economic Theory. New York: New York University Press, 519-42.

Dasgupta, P., David, P.A., 1994. Toward a new economics of science. Research Policy 23, 487-521.

Dewatripont, M., Ginsburgh, V., Legros, P., Walckiers, A., 2006. Study on the Economic and Technical Evolution of the Scientific Publication Markets in Europe. Available at the website http://ec.europa.eu/research/science-society/pdf/scientific-publicationstudy_en.pdf

Edlin, A., Edlin, N., Rubinfeld, D.L., 2004. Exclusion or efficient pricing: the 'big deal' bundling of academic journals. Antitrust Law Journal 72, 119-157.

Ehrenberg, R.G., 1991. Academic labor supply. In: Clotfelter, C., Ehrenberg, R., Getz, M., Siegfried, J. (Eds.). Economic Challenges in Higher Education. Chicago: University of Chicago Press, 143-258.

European Commission, 2003. Executive summary and conclusions of the project "Brain drain - emigration flows for qualified scientists". Available at the website http://ec.europa.eu/research/era/pdf/indicators/merit_exsum.pdf

Florida, R., 1999. The role of the university: leveraging talent, not technology. Issues in Science and Technology 15, 67-73.

Grossman, G., 2004. The distribution of talent and the pattern and consequences of international trade. Journal of Political Economy 112, 209-239.

Grossman, G., Maggi, G., 2000. Diversity and trade. American Economic Review 90, 1255-1275.

Guesnerie, R., Laffont, J.-J., 1984. A complete solution to a class of principal-agent problems with an application to the control of a self-managed firm. Journal of Public Economics 25, 329-369.

Jeon, D.-S., Laffont, J.-J., 1999. The efficient mechanism for downsizing the public sector. World Bank Economic Review 13, 67-88.

Jeon, D.-S., Laffont, J.-J., 2006. Labor market information acquisition and downsizing. Review of Development Economics 10, 345-364.

Jeon, D.-S., Menicucci, D., 2006. Bundling electronic journals and competition among publishers. Journal of the European Economic Association 4, 1038-1083.

Kwok, V., Leland, H., 1982. An economic model of the brain drain. American Economic Review 72, 91-100.

Kremer, M., 1993. The O-ring theory of economic development. Quarterly Journal 
of Economics 108, 551-575.

Laffont, J.-J., Tirole, J., 1993. A Theory of Incentives in Procurement and Regulation. Cambridge: MIT Press.

Lazear, E.P., 2005. Entrepreneurship. Journal of Labor Economics 23, 649-680.

Levin, S., Stephan, P., 1991. Research productivity over the life cycle: evidence from american scientists. American Economic Review 81, 114-132.

Merton, R.K., 1957. Priorities in scientific discovery: a chapter in the sociology of science. American Sociological Review 22, 639-59.

Merton, R.K., 1968. Behavior patterns of scientists. American Scientist 58, 1-23. Reprinted in: Merton, R.K. (Ed.) 1973. The Sociology of Science: Theoretical and Empirical Investigations. Chicago: University of Chicago Press, 325-41.

Merton, R.K., 1973. The Sociology of Science: Theoretical and Empirical investigations. Chicago: University of Chicago Press.

Murphy, K.J., 1999. Executive compensation. In: Ashenfelter, O., Card, D. (Eds.). Handbook of Labor Economics, Vol. IIIB. Amsterdam: Elsevier, 2485-2563.

Murphy, K., Shleifer, A., Vishny, R.W., 1991. The allocation of talent: the implications for growth. Quarterly Journal of Economics 106, 503-30.

National Science Board, 2004. Science and Engineering Indicators. Available at the website http://www.nsf.gov/statistics/seind04/pdfstart.htm

New York Times, 2004. National Science Panel Warns of Far Too Few New Scientists, May 5, page A24.

New York Times, 2005. Doesn’t Anyone Want to Manage Harvard's Money? August 5, page $\mathrm{C} 1$.

Perotti, R., 2002. The Italian university system: rules vs. incentives. Available at the website http://www.igier.uni-bocconi.it/whos.php?vedi=1653\&tbn=albero\&id_folder=177

Rochet, J.-C., Stole, L., 2002. Nonlinear pricing with random participation. Review of Economic Studies 69, 277-311.

Rosen, S., 1981. The economics of superstars. American Economic Review 71, 84558.

Rosenberg, N., 2004. Science and technology: which way does the causation run? Available at the website http://www.crei.cat/activities/sc_conferences/23/papers/rosenberg.pdf

Stephan, P.E., 1996. The economics of science. Journal of Economic Literature 34, 1199-1235.

Stokes, D., 1997. Pasteur's Quadrant. Washington, D.C.: Brookings Institution Press. 
Stigler, G.J., 1988. Memoirs of an Unregulated Economist. New York: Basic Books.

Thursby, J.G., Thursby, M.C., 2003. Patterns of research and licensing activity of science and engineering faculty. In: Ehrenberg, R., Stephan, P. (Eds.). Science and the University. Madison: University of Wisconsin Press, forthcoming.

Wall Street Journal Europe. (2004). "The Brain drain", September 3, page R1.

Zumeta, W., Raveling, J.S., 2002. The best and brightest for science: is there a problem here?", Commission on Professional in Science and Technology (CPST), Washington.

\section{Appendix}

\section{Proof of Proposition 1}

The first order conditions (1)-(2) are necessary and sufficient for the optimality of an interior allocation since $S W$ is strictly concave in $\left(\phi_{T}, \phi_{N}\right)$. Hence, (3) is optimal if it is interior, which is the case if and only if $\gamma>S_{\theta}-\Pi_{\theta}>-\gamma$ for $\theta \in\{N, T\}$.

\section{Proof of Proposition 2}

Let $B=\frac{1}{2 \gamma}\left\{\Pi_{T}-\Pi_{N}-\Delta p^{S}\left(2 q_{r}-1\right) \bar{b}+\alpha\left[\Delta p^{R}-\Delta p^{S}\left(2 q_{r}-1\right)\right]\right\}$ for the sake of brevity and define the Lagrangian function by $L \equiv S W+\mu\left(\phi_{N}-\phi_{T}-B\right)$, where $\mu$ is the multiplier associated with (7). Then, the first-order conditions are given by ${ }^{30}$

$$
\begin{aligned}
\frac{\partial L}{\partial \phi_{T}} & =\nu\left(-\Pi_{T}+S_{T}+\gamma\left(1-2 \phi_{T}\right)\right)-\mu=0, \\
\frac{\partial L}{\partial \phi_{N}} & =(1-\nu)\left(-\Pi_{N}+S_{N}+\gamma\left(1-2 \phi_{N}\right)\right)+\mu=0 .
\end{aligned}
$$

It is straightforward to find $\phi_{T}^{*}=\frac{\nu\left(S_{T}-\Pi_{T}+\gamma\right)-\mu^{*}}{2 \nu \gamma}=\phi_{T}^{F B}-\frac{\mu^{*}}{2 \nu \gamma}$ and $\phi_{N}^{*}=\frac{(1-\nu)\left(\gamma-\Pi_{N}+S_{N}\right)+\mu^{*}}{2(1-\nu) \gamma}=$ $\phi_{N}^{F B}+\frac{\mu^{*}}{2(1-\nu) \gamma}$ from (19)-(20). If $\mu=0$, then we obtain $\left(\phi_{T}^{F B}, \phi_{N}^{F B}\right)$ provided that (7) is satisfied at $\left(\phi_{T}, \phi_{N}\right)=\left(\phi_{T}^{F B}, \phi_{N}^{F B}\right)$. When $q_{r}>\hat{q}_{r}$ we have that $\Delta p^{R}-\Delta p^{S}\left(2 q_{r}-1\right)<0$, and (7) holds at $\left(\phi_{T}^{F B}, \phi_{N}^{F B}\right)$ if $\alpha$ is large enough. If (7) is violated at $\left(\phi_{T}^{F B}, \phi_{N}^{F B}\right)$, then $\mu^{*}>0$ and (7) binds at $\left(\phi_{T}^{*}, \phi_{N}^{*}\right)=\left(\phi_{T}^{F B}-\frac{\mu^{*}}{2 \nu \gamma}, \phi_{N}^{F B}+\frac{\mu^{*}}{2(1-\nu) \gamma}\right)$. Plugging these values into (7) yields $\mu^{*}=2 \nu(1-\nu) \gamma\left(B+\phi_{T}^{F B}-\phi_{N}^{F B}\right)>0$ and (9). We find that $\left(\phi_{T}^{*}, \phi_{N}^{*}\right)$ is interior if and only if $2 \gamma(1-\nu B)>\nu\left(\gamma-\Pi_{T}+S_{T}\right)+(1-\nu)\left(\gamma-\Pi_{N}+S_{N}\right)>2 \gamma(1-\nu) B$, a condition that is satisfied if $\gamma$ is sufficiently large. Since $\mu^{*}>0$, we obtain (iia). Result (iib) holds because $B>0$ when $\alpha=0$ or $\alpha$ is close to zero, by assumption 2. About

\footnotetext{
${ }^{30}$ Since $S W$ is strictly concave and $(7)$ is linear, the first order conditions for the Lagrangian are necessary and sufficient for the optimality of an interior allocation.
} 
result (iic) we note that as $q_{r}$ increases or $\bar{b}$ increases, $B$ decreases and therefore $\phi_{T}^{*}$ increases: see (9). When $\alpha$ increases, $B$ increases or decreases depending on whether $\Delta p^{R}-\Delta p^{S}\left(2 q_{r}-1\right)>0$ or $\Delta p^{R}-\Delta p^{S}\left(2 q_{r}-1\right)<0$, which is equivalent to saying $q_{r}<\hat{q}_{r}$ or $q_{r}>\hat{q}_{r}$.

\section{Proof of Proposition 3}

(i) The proof is done in the main text.

(ii) Without the opportunity, the contribution to social welfare of a type $\theta$ scientist is $S_{\theta}$. After the opportunity is introduced, and given the change in the research pattern, the contribution of the same type $\theta$ scientist is $S_{\theta}+\left(p_{\theta}^{S}-\Delta_{\theta}\right) y_{b}+\Delta_{\theta} y_{b}^{S}$. This is larger than $S_{\theta}$ if $y_{b}^{S} \geq 0$, or if $y_{b}^{S}<0$ and $y_{b}>\frac{\Delta_{\theta}}{p_{\theta}^{S}-\Delta_{\theta}}\left|y_{b}^{S}\right|$.

\section{Proof of Proposition 4}

(i) We analyze only the non-trivial Case 2 in which $y_{b}<\bar{y}_{b}^{P}$, because the licensing opportunity does not affect the research pattern in Case 1, and then the monetary (nonmonetary) reward to talent increases by $\delta \Delta p^{S} y_{b}>0$ (does not change). The inequality $y_{b}<\bar{y}_{b}^{P}$ requires $\bar{y}_{b}^{P}>0$, which is satisfied if and only if $\bar{b}+\alpha \leq \delta y_{a}$ holds, or $\bar{b}+\alpha>\delta y_{a}$ and $q_{r}$ is close enough to 1 . Arguing as in subsection 3.2, we find the incentive constraints that $(w, b)$ needs to satisfy in order to implement a given interior allocation $\left(\phi_{T}, \phi_{N}\right)$ :

$$
\begin{aligned}
\Pi_{T}+\alpha p_{T}^{R}+2 \gamma \phi_{T}-\gamma= & w+\delta\left[\left(p_{T}^{S}-\Delta_{T}\right) y_{b}+\Delta_{T} y_{a}\right] \\
& +\left(\beta_{T}-\left(2 q_{r}-1\right) \Delta_{T}\right)(b+\alpha) \\
\Pi_{N}+\alpha p_{N}^{R}+2 \gamma \phi_{N}-\gamma= & w+\delta\left[\left(p_{N}^{S}-\Delta_{N}\right) y_{b}+\Delta_{N} y_{a}\right] \\
& +\left(\beta_{N}-\left(2 q_{r}-1\right) \Delta_{N}\right)(b+\alpha) .
\end{aligned}
$$

After solving (21)-(22) with respect to $(w, b)$, we find that $b \leq \bar{b}$ reduces to

$$
\begin{gathered}
\Pi_{T}-\Pi_{N}+2 \gamma\left(\phi_{T}-\phi_{N}\right)+\alpha \Delta p^{R} \leq \\
\delta\left[\left(\Delta_{T}-\Delta_{N}\right)\left(y_{a}-y_{b}\right)+\Delta p^{S} y_{b}\right]+\left(2 q_{r}-1\right)\left(\Delta p^{S}-\Delta_{T}+\Delta_{N}\right)(\bar{b}+\alpha) .
\end{gathered}
$$

With respect to $(7)$, the right hand side of (23) includes the additional term $\delta\left[\left(\Delta_{T}-\right.\right.$ $\left.\left.\Delta_{N}\right)\left(y_{a}-y_{b}\right)+\Delta p^{S} y_{b}\right]+\left(2 q_{r}-1\right)\left(\Delta_{N}-\Delta_{T}\right)(\bar{b}+\alpha)$. Therefore, (23) is less restrictive than (7) if and only if $\delta\left[\left(\Delta_{T}-\Delta_{N}\right) y_{a}+\left(\Delta p^{S}-\Delta_{T}+\Delta_{N}\right) y_{b}\right]+\left(2 q_{r}-1\right)\left(\Delta_{N}-\Delta_{T}\right)(\bar{b}+\alpha)>0$, which is equivalent to

$$
y_{b}>\hat{y}_{b} \equiv \frac{\left(\Delta_{T}-\Delta_{N}\right)\left[\left(2 q_{r}-1\right)(\bar{b}+\alpha)-\delta y_{a}\right]}{\delta\left(\Delta p^{S}-\Delta_{T}+\Delta_{N}\right)}=\frac{\left(\Delta_{N}-\Delta_{T}\right) \bar{y}_{b}^{P}}{\delta\left(\Delta p^{S}+\Delta_{N}-\Delta_{T}\right)},
$$


given that $\Delta p^{S}-\Delta_{T}+\Delta_{N}=p_{T}^{S}-\Delta_{T}-\left(p_{N}^{S}+\Delta_{N}\right)>0$. Suppose first that $\Delta_{T} \geq \Delta_{N}$. Then $\hat{y}_{b} \leq 0$ because $\bar{y}_{b}^{P}>0$ and thus (24) is satisfied; in this case, providing the licensing opportunity relaxes the constraint $b \leq \bar{b}$ and therefore reduces the brain drain. Suppose now that $\Delta_{T}<\Delta_{N}$. Then $0<\hat{y}_{b}<\bar{y}_{b}^{P}$ and the licensing opportunity reduces the brain drain if and only if $\hat{y}_{b} \leq y_{b}<\bar{y}_{b}^{P}$.

(ii) The proof is straightforward and is omitted.

\section{Proof of Proposition 5}

(i) As we have mentioned after introducing $S W^{S}$, we obtain $m_{T}^{e}=\Pi_{T}+2 \gamma \phi_{T}-\gamma+$ $\alpha p_{T}^{R}-\alpha \beta_{T}, m_{N}^{e}=\Pi_{N}+2 \gamma \phi_{N}-\gamma+\alpha p_{N}^{R}-\alpha \beta_{N}$ from (14)-(15) and plug them into $S W^{S}$. In this way we obtain a concave function of $\left(g_{G}, g_{B}\right)$, and thus the first order conditions (16)-(17) are necessary and sufficient for maximization.

(ii) Since $p_{T}^{S}$ and $p_{N}^{S}$ are concave [by assumption $5\left(\right.$ ii)], which means that $\frac{d p_{T}^{S}}{d g}$ and $\frac{d p_{N}^{S}}{d g}$ are decreasing, it is straightforward to see from (16)-(17) that $g_{G}^{*}$ and $g_{B}^{*}$ are decreasing in $k$. Thus, $m_{T}^{e *}$ and $m_{N}^{e *}$ are increasing in $k$.

(iii) We find that $\frac{\partial k}{\partial \alpha}<0, \frac{\partial k}{\partial q_{r}}<0$ and $\frac{\partial k}{\partial \lambda}=\frac{s^{H}-s^{L}-\alpha\left(2 q_{r}-1\right)}{\left(s^{H}-s^{L}+\alpha \lambda\left(2 q_{r}-1\right)\right)^{2}} ; \frac{\partial k}{\partial \lambda}>0$ since $s^{H}-s^{L}>\alpha$.

\section{Proof of Proposition 6}

We notice that (18) is positive if and only if $\phi_{T}<\phi_{N}+\frac{\alpha}{2 \gamma}\left(\beta_{T}-\beta_{N}-\Delta p^{R}\right)$. We prove below that $\beta_{T}-\beta_{N}>\left(2 q_{r}-1\right) \Delta \underline{p}^{S}$, thus $\phi_{T} \leq \phi_{N}+\Phi$ implies that (18) is positive. Finally, $\Phi>0$ if and only if $q_{r}>\underline{q}_{r}$. In order to prove that $\beta_{T}-\beta_{N}>\left(2 q_{r}-1\right) \Delta \underline{p}^{S}$, we use (12)-(13):

$$
\begin{aligned}
\beta_{T}-\beta_{N} & =\left(2 q_{r}-1\right)\left[q_{s} p_{T}^{S}\left(g_{G}^{*}\right)+\left(1-q_{s}\right) p_{T}^{S}\left(g_{B}^{*}\right)-q_{s} p_{N}^{S}\left(g_{B}^{*}\right)-\left(1-q_{s}\right) p_{N}^{S}\left(g_{G}^{*}\right)\right] \\
& =\left(2 q_{r}-1\right)\left[p_{T}^{S}\left(g_{B}^{*}\right)-p_{N}^{S}\left(g_{B}^{*}\right)+\int_{g_{B}^{*}}^{g_{G}^{*}}\left(q_{s} \frac{d p_{T}^{S}(g)}{d g}-\left(1-q_{s}\right) \frac{d p_{N}^{S}(g)}{d g}\right) d g\right] \\
& >\left(2 q_{r}-1\right)\left[p_{T}^{S}\left(g_{B}^{*}\right)-p_{N}^{S}\left(g_{B}^{*}\right)\right] \geq\left(2 q_{r}-1\right)\left[p_{T}^{S}(\underline{g})-p_{N}^{S}(\underline{g})\right]=\left(2 q_{r}-1\right) \Delta \underline{p}^{S}
\end{aligned}
$$

where the two inequalities hold because of assumption 5 and $q_{s}>\frac{1}{2}$. 


\section{Set of implementable allocations under asymmetric information}

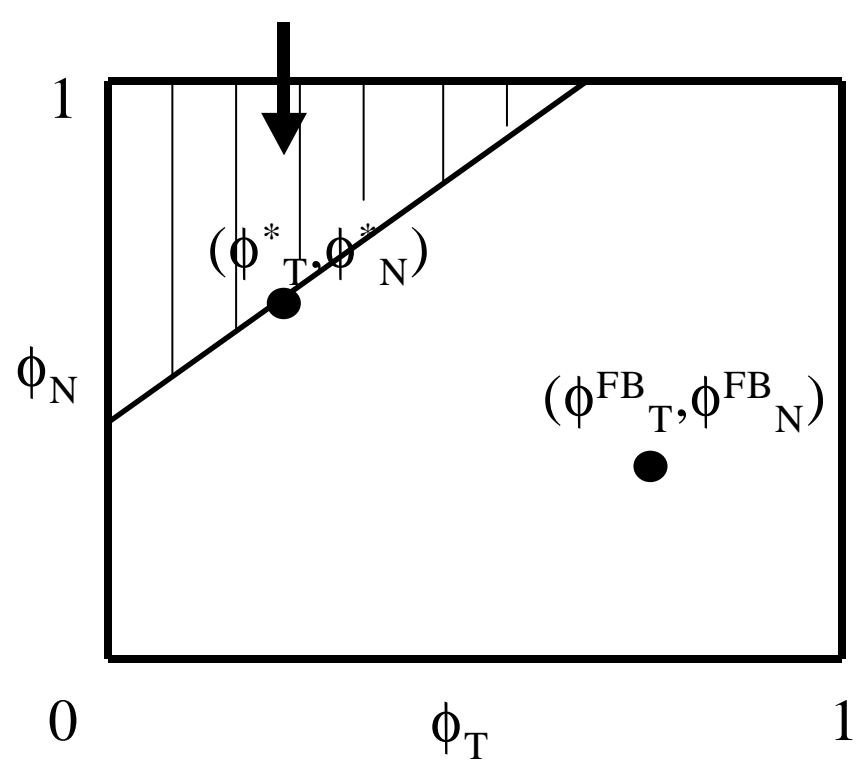

Figure 1: The first-best and the second-best allocations of talent in the absence of fame 